\title{
Executive Functions in Late Adolescence and Early Adulthood and their Relationship with Risk-Taking Behavior
}

James M. Ogilvie ${ }^{1 \dagger}$, David H.K. Shum ${ }^{2,3}$ and Anna Stewart ${ }^{1,4}$

${ }^{1}$ Griffith Criminology Institute, Griffith University

${ }^{2}$ Department of Rehabilitation Sciences, The Hong Kong Polytechnic University

${ }^{3}$ School of Applied Psychology, Griffith University

${ }^{4}$ School of Criminology and Criminal Justice, Griffith University

${ }^{\dagger}$ Corresponding author

j.ogilvie@griffith.edu.au

ORCID: 0000-0003-2294-5665

176 Messines Ridge Road

Griffith Criminology Institute, Griffith University

Mount Gravatt, QLD 4122 AUSTRALIA

David Shum ORCID: 0000-0002-4810-9262

Anna Stewart ORCID: 0000-0002-5256-0400

Citation: Ogilvie, J. M., Shum, D. H. K., \& Stewart, A. (2020). Executive Functions in Late Adolescence and Early Adulthood and Their Relationship with Risk-Taking Behavior. Developmental Neuropsychology, 1-23.

doi:10.1080/87565641.2020.1833885 


\begin{abstract}
Executive functions (EF) continue developing throughout adolescence, with immaturity in EF theorized to underlie risk-taking. 129 older adolescents and young adults (aged 17 to 22 years) were assessed using a battery of cool and hot EF tasks, and a behavioral measure of risk-taking propensity. Minimal age-related differences in EF performance were evident, confirming they were largely functionally mature by mid-adolescence. Inconsistent with the predictions of imbalance models of adolescent development, weaker EF was not associated with greater risk-taking propensity. The findings suggest that during later adolescence and early adulthood, not all forms of risk-taking are associated with EF.
\end{abstract}

Keywords: executive functions, risk-taking, adolescence, development, cognition 
Executive functions (EF) are a set of general-purpose control mechanisms that regulate human behavior, cognition and emotion, and can be considered core components of self-regulation abilities (Miyake \& Friedman, 2012). EFs have been some of the most intensively studied neuropsychological constructs in the last two decades, and it is often postulated that these abilities continue to develop throughout adolescence and into early adulthood. It is often noted in structural brain imaging studies that significant reorganization in grey and white matter occurs throughout adolescence and into early adulthood, particularly in frontal regions and structures connecting to these regions (Caballero, Granberg, \& Tseng, 2016; Giedd, 2004). These changes are assumed to underlie cognitive development, including the maturation of EF, with an implication that these abilities do not reach functional maturity until structural development is complete. However, few studies have sought to link structural brain changes to functional behavioral changes as measured by neuropsychological tests or other behavioral measures. Connected to this, immaturity in EF is often proposed to play a role in characteristic behaviors of adolescence, including sensation-seeking, risk-taking and antisocial behavior. Despite these popular views, limited research has focused on examining potential developmental changes in EF that may continue throughout adolescence and how they may shape risk-taking behavior.

The current study represents an effort to examine potential neuropsychological changes in different forms of EF (i.e., "hot" and "cool" processes) that may occur across later adolescence and into early adulthood and examine whether EF is associated with risk-taking behavior. There is limited evidence regarding the maturation of EF during adolescence and into early adulthood, despite the often- 
postulated protracted course of development for the neural substrates thought to underlie these functions.

\section{Development of Executive Functions}

It is well established that most EF abilities are functionally mature by midadolescence (Huizinga, Dolan, \& van der Molen, 2006; Lee, Bull, \& Ho, 2013; Prencipe et al., 2011). The greatest and most rapid developmental changes in EF typically occur in childhood, and continue at a decreased and more gradual rate into adolescence and early adulthood (Best \& Miller, 2010; Brocki \& Bohlin, 2004; Romine \& Reynolds, 2005). Evidence also indicates that EF can be fractionated into component processes that follow distinct trajectories of development, with adult-level performance on different $\mathrm{EF}$ tasks reached at different rates and ages during childhood and adolescence (Luna, Garver, Urban, Lazar, \& Sweeney, 2004; Romine \& Reynolds, 2005). Due to methodological differences across studies (e.g., tasks and samples used) as well as individual differences in rates of development, it is not possible to unequivocally demark precise timings of typical development for specific EF component process.

Some of the most commonly examined EFs include inhibition and working memory (Friedman \& Miyake, 2017). Inhibition appears to exhibit significant early developmental gains in development during childhood, while working memory and shifting exhibit more gradual linear improvements throughout childhood and adolescence (Best $\&$ Miller, 2010). However, most evidence regarding the developmental progression of EF components has been derived from samples aged from childhood up to early- to mid-adolescence. There have been relatively few 
studies examining the potential progression of development using older adolescent and early adult samples.

Available evidence indicates that maturation of some EF abilities extends into later adolescence and early adulthood. For example, Luna et al. (2004) measured cognitive maturation in a sample aged eight- to 30 -years, with results suggesting that mature adult-level performance was reached at different times for processing speed (15 years), response inhibition (14-years) and working memory (19-years) abilities. Huizinga et al. (2006) examined age-related changes in the EF components of working memory, shifting and inhibition in four groups of youth aged seven-, 11-, 15and 21-years. They found that EF components mature at different rates, with performance on EF tasks measuring working memory and shifting ability improving up to about 15 -years and some aspects of inhibitory control continuing to improve up to age 21-years. Huizinga et al. (2006) further found that performance on more complex EF tasks (e.g., Wisconsin Card Sorting Task, Tower of London) continued to improve into early adulthood. Overall, available studies indicate that adult levels of mature performance on EF measures is reached by mid-adolescence (i.e., around 15years). However, there is some evidence to suggest that working memory (Luna et al., 2004) and inhibition (Huizinga et al., 2006) EF components continue to develop into late adolescence.

\section{Executive Functions in Affective and Motivational Contexts}

Current dominant theories of adolescent neurodevelopment and behavior are best characterized as developmental mismatch or imbalance models, including dual system (Shulman et al., 2016) and triadic (Ernst, 2014) models. Developmental imbalance models emphasize the relatively earlier maturation of subcortical affective 
brain regions in comparison to more slowly maturing cognitive control frontalcortical brain regions to explain why adolescents may be more likely to make more emotional and sub-optimal decisions, resulting in risky behavior (Casey, Getz, \& Galván, 2008; Steinberg, 2008). Based on this model of neurological maturation, adolescence is typically characterized as a period of heightened sensitivity to reward and relative immaturity in cognitive control and self-regulation, which in combination results in a predisposition toward engagement in sensation seeking and risk-taking behaviors. Consistent with imbalance models, there is fairly consistent evidence that sensation seeking (i.e., an outcome of increased sensitivity to reward) increases during adolescence to peak at about 19-years, while self-regulation capacity increases steadily from preadolescence into early adulthood to plateau in the mid-20s (Steinberg et al., 2018).

Despite adolescence being characterized as a period of imbalance between affective/approach and cognitive control systems, limited research has examined the developmental trajectories of hot EF abilities, or cognitive control under emotionladen circumstances. Hot EF tasks involve stimuli, decisions and outcomes that have motivational and emotional salience. These tasks are believed to more closely represent the construct of EF in the context of everyday decision-making, which typically occurs under conditions of motivational and emotional significance (Zelazo \& Carlson, 2012). Available evidence with adults indicates that performance on hot and cool EF tasks is dissociable, and that impairments in hot EF can occur independently of cool EF and vice versa (Bechara, Damasio, Tranel, \& Anderson, 1998).

There has been limited research examining developmental changes in hot EF task performance during adolescence and early adulthood. Zelazo, Craik, and Booth 
(2004) hypothesized that adolescents will exhibit marked difficulty in tasks requiring EF under conditions of emotional and motivational significance, with hot EF abilities continuing to develop into early adulthood. Prencipe et al. (2011) have conducted one of the few studies to examine the development of hot and cool EF abilities across adolescence, using a sample of youth aged eight- to 15-years. They found that developmental changes in hot EF (i.e., measured by the Iowa Gambling Task) occurred later in the age range than changes in cool EF, suggesting that hot and cool EF abilities follow separate trajectories of development. However, these findings do not provide insight into whether the development of hot $\mathrm{EF}$ abilities continues into later adolescence and early adulthood. To date, few studies have examined whether hot $\mathrm{EF}$ abilities continue to develop into early adulthood, which is a period when rates of engagement in risk-taking and antisocial behaviors peak (DeLisi \& Piquero, 2011). Strong evidence is yet to be produced regarding the potential separability of hot and cool EF during adolescence, and how such functions may follow separate developmental trajectories into later adolescence and early adulthood.

\section{Executive Function and Risk-Taking Behavior in Adolescence}

Adolescents engage in a disproportionate amount of risk-taking and reckless behavior compared to children and adults (Steinberg, 2004). These behaviors often involve breaking age-related societal norms or laws, such as under-age drinking, substance use or sexual activity. Early attempts to explain adolescent increases in risk-taking focused on the role of developmental changes in cognitive reasoning and rational decision-making abilities, with a presumption that increased engagement in risk-taking was a result of immature and/or deficient cognitive reasoning abilities (Ernst \& Paulus, 2005). However, heightened rates of risk-taking cannot be simply 
explained in terms of immaturity of cognitive reasoning or decision-making processes, with empirical evidence largely not supporting these hypotheses (Crone, van Duijvenvoorde, \& Peper, 2016; Romer, Reyna, \& Satterthwaite, 2017). The information processing and decision-making abilities of adolescents are comparable to adult levels in controlled or laboratory settings, with adolescents being no worse than adults in perceiving risk and their vulnerability to these risks (Romer et al., 2017; Willoughby, Good, Adachi, Hamza, \& Tavernier, 2013). Therefore, adolescents are capable of assessing potential costs of risk-taking comparable to adults, but they still present with a greater propensity for engaging in risk-taking behaviors.

As noted, contemporary models of adolescent development propose that high rates of risk-taking among adolescents relative to children and adults are largely attributable to an imbalance between heightened sensitivity to reward and immature inhibitory/self-control control systems (Shulman et al., 2016). A key prediction of these models is that adolescent risk-taking behavior is associated with weaker cognitive control in the context of heightened reward sensitivity, and that risk-taking will decline as cognitive control matures/strengthens. This prediction shares similarities to early attempts to explain adolescent risk taking in the assumption that cognitive immaturity underlies risk-taking. Correspondingly, the evidence to support imbalance model predictions is mixed.

Consistent with the predictions of imbalance models, Duell et al. (2016) found that stronger self-regulation as measured by EF tasks (i.e., Tower of London and Stroop tasks) was associated with lower risk-taking on a behavioral task in a crossnational sample of individuals aged 10 though 30 years. Further, Reynolds, Basso, Miller, Whiteside, and Combs (2019) found a robust relationship between EF task performance (i.e., Iowa Gambling Task [IGT] and Wisconsin Card Sorting Test 
[WCST] and self-reported risk-taking behaviors in a sample of healthy young adults (mean age 20.82-years). Worse performance on the WCST was associated with greater self-reported sexual risk-taking and drug and alcohol-related behaviors, and worse performance on the IGT was associated with greater self-reported antisocial acts. These findings provide some preliminary evidence that poorer EF performance is associated with greater risk-taking.

In contrast to the predictions made by imbalance models, there is also evidence to suggest that stronger cognitive control (i.e., better EF performance) is associated with greater risk-taking during adolescence. For example, Romer et al. (2011) found that sensation-based risk-taking rose in conjunction with strengthening EF (i.e., working memory) across early- to mid-adolescence (i.e., sample followed from 10-12 years to 12-14 years). Similarly, Blair, Moyett, Bato, DeRosse, and Karlsgodt (2018) found that greater working memory was associated with better performance on an adaptive risk-taking task (i.e., the Balloon analogue risk task) in a sample of youth aged 8 to 25 years. These seemingly divergent findings suggest the possibility that not all risk-taking is associated with deficits or immaturities in $\mathrm{EF} /$ cognitive control.

There is accumulating evidence that not all adolescent risk-taking is associated with deficits or immaturity in cognitive control (Crone et al., 2016). In this regard, it is important to distinguish between different types of risk-taking, and how these may change across development. For example, Romer et al. (2017) describe three different patterns of decision-making tendencies under risk conditions: known, ambiguous and insensitive risk-taking; with each having unique motivational and cognitive underpinnings. Insensitivity to risk is argued to increase the chances of impulsive action in the presence of risk-taking opportunities, and a result of weak/deficient 
cognitive control. It has been argued that this form of risk-taking is only characteristic of a subgroup of youth experiencing EF and self-control deficits that were present prior to adolescence and likely to persist into adulthood (Bjork \& Pardini, 2015). This is the form of risk-taking that imbalance models are better suited to explain (Romer et al., 2017). Risk-taking under conditions of known risk is argued not to peak during adolescence, but rather decrease linearly from childhood and into adulthood. Finally, risk-taking under conditions of ambiguity is argued to peak during adolescence, being tied to sensation-seeking and a drive for exploration that may confer benefits to adolescents, assisting their adaptation to changing circumstances and environments (Romer et al., 2017; Tymula, Rosenberg Belmaker, Ruderman, Glimcher, \& Levy, 2013). This has led some to argue that under ambiguous risky decision-making circumstances, improving EF abilities may facilitate "successful" or adaptive engagement in risk-taking actions (Romer et al., 2017). However, while there is evidence to indicate that distinct neural mechanisms underlie risk-taking under known and ambiguous conditions, behavioral evidence is mixed about whether risk-taking under conditions of ambiguity peaks during adolescence (Blankenstein, Schreuders, Peper, Crone, \& van Duijvenvoorde, 2018; Li, 2017). It has been documented that different measures of risk-taking do not always correlate strongly together (Mamerow, Frey, \& Mata, 2016), which may account for the variability in findings across studies.

\section{Aims of Current Research}

Casey et al. (2008) argue that determining developmental trajectories for cognitive abilities is an essential task in characterizing adolescent transitions and changes in behavior during this period. The first aim was to examine the 
developmental progression of EF during late adolescence and early adulthood in a typically developing sample of youth, with a focus on the distinction between cool and hot EF abilities. A battery of EF tasks was administered to a sample of youth aged 17 to 22 years. Guided by available evidence on the development of EF during adolescence, two hypotheses were posed: 1) Cool EF abilities will be functionally mature across the age-range studied with no age-related changes evident; and 2) Developmental improvements in performance on hot EF tasks will occur later than changes in performance on comparatively cool EF tasks, with these changes being evident from late adolescence into early adulthood.

The second aim was to examine whether individual differences in EF performance during late adolescence/early adulthood were able to predict the propensity to engage in risk-taking under conditions of ambiguity when also taking reward sensitivity into account. Adolescence is documented as a period of heightened risk-taking, with dominant models of development proposing this is due to a maturational imbalance between an early arising sensitivity to reward and delayed cognitive maturation of self-regulation abilities. Guided by this key argument of developmental imbalance models, it was hypothesized that increased risk propensity would be associated with weaker cognitive control or EF performance. The focus on late adolescence and early adulthood (i.e., 17- to 22-years) was informed by this age range typically representing a period of peak engagement in risk-taking, and therefore being a critical developmental stage to test imbalance model predictions.

\section{Methods}

\section{Participants}


Participants were 129 older adolescent and young adults (62 males) aged 17 to $22($ mean $=19.29, \mathrm{SD}=1.63)$ recruited from a major metropolitan university in Brisbane, Australia. There was no significant difference across sex in age, $t(127)=$ $0.29, p=.77$. The sample was predominately Caucasian $(72.1 \%)$, with a grade 12 level of education (82.2\%). All participants were compensated for their participation with a single movie voucher, which also functioned as a motivational incentive for the risk-taking measure that will be described subsequently.

To be eligible for participation, individuals were required to demonstrate proficiency in the English language (i.e., ten or more years of education with English as the instructional language), have normal or corrected to normal vision and hearing, not be color blind, and have an estimated full-scale IQ of 70 or above according to the Wechsler Abbreviated Scales of Intelligence (WASI), First Edition (Psychological Corporation, 1999). Three individuals were excluded from participation due to fewer than ten years of English language education. One individual chose to withdraw from participation due to believing the cognitive assessment would be overly fatiguing. These four individuals were separate from the final sample of 129 participants.

\section{Measures}

\section{General intellectual functioning}

General intelligence was estimated as a potential covariate using the twosubtest form (i.e., vocabulary and matrix reasoning) of the Wechsler Abbreviated Scale of Intelligence (WASI) First Edition (Psychological Corporation, 1999). There was no significant difference across age groups in mean FSIQ scores, $F(5,123)=$ $0.99, p=.43$, with the mean FSIQ for the total sample being $108.18(S D=10.38)$. 


\section{Reward Sensitivity}

Reward sensitivity is a core aspect of imbalance theories and was assessed as a potential factor impacting the association between EF and risk-taking using two selfreport measures. First, the 24-item self-report behavioral activation and inhibition scales (BIS/BAS scales; Carver \& White, 1994) were used to assess individual differences in sensitivities to reward. Greater behavioral approach sensitivity (BAS) reflects individuals that are strongly motivated to approach and pursue rewards and is separated into three subscales: BAS drive (four items, $\omega=.79$ ); BAS fun seeking (four items, $\omega=.71$ ); and BAS reward responsiveness (five items, $\omega=.74$ ). Greater behavioral inhibition sensitivity (BIS) is the converse of BAS and reflects individuals that are highly motivated toward escape and avoidance in situations of conflict or uncertainty. The BIS is represented by a single scale on the measure (seven items, $\omega=$ .77). The BIS/BAS scales have been used successfully with adolescents as a selfreport instrument (Morgan, Bowen, Moore, \& van Goozen, 2014). Second, a modified 6-item $(\omega=.73)$ version of Zuckerman's sensation seeking scale (Steinberg et al., 2008; Zuckerman, Eysenck, \& Eysenck, 1978) was used to assess reward sensitivity as operationalized as a self-reported sensation seeking trait. McDonald's (1999) omega values for the BIS/BAS and sensation seeking scales (reported above) were in the moderate range, suggesting adequate internal reliability.

\section{Executive function}

A battery of measures was put together using tasks derived from the Cambridge Neuropsychological Test Automated Battery (CANTAB) and the DelisKaplan Executive Function System (D-KEFS) to gain a comprehensive assessment of EF processes as a multi-component system. Four tasks were drawn from the 
CANTAB, including the stop signal task (SST), spatial working memory (SWM), intra-extra dimensional set shift (IED), and the Cambridge gambling task (CGT). Each of the CANTAB tasks were computerized.

Stop Signal Task. The SST was used to measure inhibition. Participants are required to press a left button when a left pointing arrow appeared on the screen and a right button when a right pointing arrow appeared. Participants were instructed to respond as quickly as possible while also withholding a response when an arrow was presented with an auditory signal (i.e., $25 \%$ of trials). The onset of the auditory stop signal is varied dynamically by the computer using staircase functions to establish the point where an individual is able to successfully inhibit a response on $50 \%$ of the trials. The primary measures of the SST included the proportion of successful stops and stop signal reaction time (SSRT) for the last half of trials. Supplementary outcome measures of SST included direction errors (i.e., when the wrong direction button was pressed) and median correct reaction time on go trials.

Spatial Working Memory Task. The SWM assesses an individual's ability to retain and manipulate spatial information in working memory. Participants are presented with a screen of boxes and instructed to find a number of squares hidden behind them. Total errors (within and between search errors) was used as a primary outcome measure of the efficiency of working memory on the SWM. A measure of search strategy is also used to assess working memory efficiency on the SWM and relates to the degree to which a participant employs a consistent search strategy to search the boxes, with a lower score representing better performance.

Intra/Extradimensional Shift Task. The IED is a test of rule acquisition and reversal, assessing the maintenance, shifting, and flexibility of attention. Participants are required to learn a sorting rule by selecting from a pair of stimuli appearing on the 
screen. Once a learning criterion is reached, the participant must then learn a new rule for selecting correct stimuli (i.e., extra-dimensional shift). Shifting ability (i.e., stages completed) and total adjusted errors are the primary measures of the IED. Shifting ability is assessed using the total number of stages completed, with a higher number representing a greater shifting ability. Total adjusted errors is calculated by adjusting for the total number of stages completed, since participants who do not complete all the stages have less opportunity to make errors.

Cambridge Gambling Task. The CGT is a measure of decision-making and risk-taking behavior in the context of reward, making it a measure of hot EF. Participants are presented with a row of ten red and blue boxes across the top of the screen. The proportion of red and blue boxes changes across trials, and participants are instructed to guess what color box a token will be hidden behind. Participants are asked to make as many points as possible by guessing and betting points on the correct color box a token is hidden behind for each trial. There are a number of outcome measures for the CGT that assess different aspects of decision making in a motivational context, including quality of decision-making (higher score representing better performance), delay aversion, deliberation time, overall proportion bet, risk adjustment and risk-taking. The risk-taking score represents the mean proportion of points gambled on trials where the most likely outcome was chosen, with higher scores representing greater risk-taking.

Four tasks were drawn from the D-KEFS (Delis, Kaplan, \& Kramer, 2001), including verbal fluency, trail making (TMT), color-word interference, and the tower task. All D-KEFS tasks were administered in a paper-and-pencil format.

Verbal Fluency. Verbal fluency measures an individual's ability to generate words fluently, in an effortful, phonemic format (letter fluency), from overlearned 
concepts (category fluency), and while simultaneously shifting between overlearned concepts (category switching). For all conditions, the primary outcome measure is the number of words generated for each condition, with higher scores reflecting greater verbal fluency ability. In addition, total errors are recorded across all verbal fluency conditions, which include set loss and repetition errors, with lower scores reflecting better performance.

Trail Making Task. The TMT is a visual-motor sequencing/switching task that assesses mental flexibility, visual attention and task switching. For the numberletter sequencing task, participants are required to switch between connecting numbers and letters in ascending order. Completion time in seconds is the primary outcome measure of all conditions of the TMT, with lower scores representing better performance. Errors in sequencing and switching are also recorded, with lower scores representing better performance.

Color-Word Interference Test. The color-word interference test is based on the Stroop test (Stroop, 1935) and assesses an individual's ability to inhibit an overlearned verbal response (i.e., word reading) to generate a conflicting response of naming dissonant ink colors in which words are printed. The primary outcome measures for the two conditions of inhibition and switching are completion time in seconds (lower time representing better performance) and number of errors, both corrected and uncorrected (lower number representing better performance).

Tower Task. The tower task involves spatial planning, rule learning, inhibition of perseverative responding, and the ability to establish and maintain an instructional set. The task requires participants to move disks of varying size across three pegs to match a presented tower in the fewest number of moves possible while adhering to simple rules. The primary outcome measures are the tower achievement (higher score 
representing better performance) score and the number of rule violations (lower score representing better performance).

Raw scores for CANTAB and D-KEFS outcome measures were used rather than age-scaled scores, given the purpose of analyses was to examine potential agerelated changes in EF performance.

\section{Risk-taking}

The Balloon Analogue Risk Taking (BART) task is a computerized behavioral measure of decision-making and reward processing that was used to assess risk-taking propensity under conditions of ambiguity (see Lejuez, Aklin, Zvolensky, \& Pedulla, 2003; Lejuez et al., 2002, for further details). Participants are presented with a balloon accompanied by a balloon pump, a reset button labelled "Collect $\$ \$$ ", a permanent money earned display labelled "Total Earned", and a second display presenting the money earned on the last balloon labelled "Last Balloon". Participants are presented with 30 balloons (i.e., trials) and instructed that they will be able to earn money from the balloons by pumping them up, with each pump earning five cents that accrues in a temporary reserve. Participants are told that each balloon has a different explosion point, and that they should make as much money as possible to reach an undisclosed amount of money to receive a movie ticket. All participants received the movie ticket regardless of the amount of money earned. A "pop" sound is played when a balloon is pumped past its individual explosion point and all money accrued in the temporary reserve is lost. At any point during the inflation of each balloon, participants may stop pumping the balloon and click the "Collect $\$ \$ \$$ " button to transfer the money in the temporary reserve to the permanent bank. The primary outcome measures for the BART are the adjusted number of pumps and explosions across balloons. Adjusted 
average pumps is defined as the average number of pumps excluding balloons that exploded. Higher values represent greater risk propensity. Explosions were the number of balloons pumped beyond their explosion points, with higher values representing greater risk propensity. It could be argued that adjusted average pumps represents the positive outcome of risk-taking (i.e., successfully inflating balloons more without exploding), while explosions represent the negative outcome of risktaking. Confirming its validity as a measure of risk-taking, the BART has been strongly correlated with scores on self-report measures of sensation seeking, impulsivity, deficiencies in behavioral constraint, and engagement in real-world risk taking behaviors (Aklin, Lejuez, Zvolensky, Kahler, \& Gwadz, 2005; Crowley et al., 2010; Lejuez et al., 2003; Lejuez et al., 2002; MacPherson, Magidson, Reynolds, Kahler, \& Lejuez, 2010).

\section{Procedure}

The research was conducted in accordance with the Australian National Statement on Ethical Conduct in Human Research (The National Health and Medical Research Council, 2015), and approval was obtained from the Griffith University Ethics Committee prior to commencing the research. Informed consent was obtained from individual participants before commencing task administration. The tasks were administered individually in one two-hour session in a fixed order for all participants, with task order designed to minimize disruption in switching between task modalities (i.e., computerized and paper-and-pencil) and vary task demands across tasks to maintain participants' interest and engagement. All tasks were administered according to the published standardized instructions and guidelines in a quiet, well-lit room free from distraction. 


\section{Data Management and Analytic Strategy}

Data were missing for one participant (male, 22 years) for the Stop Signal Task due to a computer malfunction. One participant (male, 22 years) had missing data for all D-KEFS tasks apart from verbal letter fluency, due to requesting assessment be discontinued because he perceived himself to be performing poorly. BART data were missing for 10 participants due to a software program malfunction, where performance data failed to be recorded. Missing data was estimated to retain participant numbers for analyses using a multiple imputation approach through the "mice” package (van Buuren \& Groothuis-Oudshoorn, 2011) for R (R Core Team, 2019) with the predictive mean matching method. Multiple imputation techniques are dependent on the number of imputations rather than sample sizes (Schafer, 1999).

Data was screened for univariate and multivariate outliers. Univariate outliers were defined as a $z$-score \pm 3 ; multivariate outliers were defined as a Mahalanobis distance exceeding the critical chi-square value based on degrees of freedom in the model (Tabachnick \& Fidell, 2014). Data were analyzed with and without outlier cases, and if the pattern of statistical significance did not vary, all cases were retained in the analyses to maintain the sample size. All univariate and multivariate outlier cases were retained across analyses due to no change in the pattern of significance with their exclusion.

Potential age differences in EF task performance were examined using bivariate correlations and Generalized Additive Models (GAM). GAMs were used to probe for possible non-linearity between age, which was measured as a continuous variable, and each of the EF task performance outcomes through the "mgcv" package (Wood, 2011) for R. Each GAM model was estimated using the restricted maximum 
likelihood method and thin plate regression splines as the smoothing term with six knots due to there being a range of six age years (i.e., 17 to 22) for participants. Significance for GAMs was assessed in relation to the smoothing term, with the significance test based on effective degrees of freedom (EDF; values close to one suggest a linear relationship and larger numbers suggest greater non-linearity).

Consistent with the wider EF research field (Friedman \& Miyake, 2017), a dimension reduction approach (i.e., factor analysis) was adopted to reduce the number of EF task outcomes for hierarchical regression analyses. Exploratory factor analysis was conducted on the EF task outcomes using the "fa" function in the "psych" package (Revelle, 2017) for R. The principal axis factoring method of estimating factor loadings was adopted, given that a number of the distributions of EF outcome variables were significantly non-normal. Oblique rotations were applied to the factor solutions to allow for correlated factors, given that current evidence emphasizes the interconnections among EF components (Miyake \& Friedman, 2012).

Hierarchical regressions were conducted to examine whether EF task performance was associated with risk-taking. To remain consistent with imbalance models, self-report measures of reward sensitivity were taken into account when examining the association between risk-taking and cognitive control. Risk-taking was examined from both a positive (i.e., adjusted average pumps) and negative (i.e., explosions) outcome approach, given the possibility that EF may be linked differentially to distinct aspects of risk-taking. Therefore, separate hierarchical regression models were estimated for both risk-taking outcomes using the same set of predictors. Each hierarchical regression was conducted in three stages to examine whether EF performance could account for risk-taking after controlling for covariates and reward sensitivity. Age, sex and general intellectual functioning were entered in 
the first stage, followed by self-report reward sensitivity measures in the second stage and the EF factors at the final stage.

\section{Results}

\section{Age Differences in Executive Function Task Performance}

Guided by available evidence on the development of EF during adolescence, it was hypothesized that cool EF performance would be stable across the age-range studied, but that changes in hot EF task performance would be evident from late adolescence into early adulthood. Means and standard deviations for EF measures, BART task and reward sensitivity self-report outcomes by the total sample and separated by sex are presented in Table 1. Age effects for all outcomes were examined using a series of GAMs (Table 1).

\section{[INSERT TABLE 1 ABOUT HERE]}

\section{Cool Executive Function}

Support for the first hypothesis was mixed. For most cool EF task outcomes, there were no significant age effects, with only color-word inhibition and switching errors, and stop signal reaction time outcomes exhibiting significant effects. Significant linear trends (as denoted by an effective degrees of freedom of 1.00) of decreasing errors with increasing age were found for both color-word inhibition, $F(1.00)=7.59, p$ $<.01, R_{a d j}^{2}=.05$, and switching, $F(1.00) 8.97, p<.01, R_{a d j}^{2}=.06$, errors, which are illustrated in Figure 1.

[INSERT FIGURE 1 ABOUT HERE] 
There was a significant linear trend of decreasing stop signal reaction times across age, $F(1.00)=4.53, p<.05, R^{2}{ }_{a d j}=.03$, which is illustrated in Figure 2. In relation to cool EF, these results indicated that some verbal and motor inhibition EF skills continued to improve gradually in the age-range studied.

\section{[INSERT FIGURE 2 ABOUT HERE]}

\section{Hot Executive Function}

No support was found for the second hypothesis of ongoing age-related changes in hot EF task performance as measured by the CGT. There were no significant effects of age for any of the CGT outcome measures.

In summary, there was mixed support for the hypothesis that cool EF would be largely mature in late adolescence and early adulthood. There were no significant age-related performance effects for most cool EF tasks except for color-word inhibition and switching errors and stop signal reaction time that measure verbal and motor inhibition abilities respectively. No support was found for the hypothesis that age-related performance effects would be evident for hot EF as measured by the CGT.

\section{Executive Function Dimension Reduction}

EFA was performed on the $27 \mathrm{EF}$ task outcomes described in Table 1 to reduce the number of variables for subsequent analyses. Full details of this analysis are provided in the supplementary materials section. A five-factor model provided the most appropriate fit to the EF task outcomes with a factor structure that was clearly interpretable (see Table 2) and accounted for $51 \%$ of the common variance in EF task 
outcomes. The five EF factors derived from the data were labelled: verbal inhibition and flexibility; spatial working memory and planning; rule acquisition and switching; risky decision-making; and motor inhibition. These factors were included in subsequent hierarchical regression analyses.

\section{[INSERT TABLE 2 ABOUT HERE]}

\section{Risk-taking}

A significant non-linear effect for age was found for BART adjusted average pumps, $F(2.85)=3.25, p<.05, R_{a d j}^{2}=.07$. Inspection of Figure 3 indicated that adjusted average pumps peaked at around age 19 years and again increased at 21-22 years. There was no significant effect of age on BART explosions.

\section{[INSERT FIGURE 3 ABOUT HERE]}

\section{Executive Functions and Risk-Taking}

Guided by developmental imbalance models, it was hypothesized that increased risk propensity would be associated with weaker cognitive control or EF performance. Correlations (i.e., Pearson's r) among the variables included in the hierarchical regressions are displayed in Table 3 . There was a very strong and significant positive correlation between BART adjusted average pumps and explosions $(r=.91)$ indicating that participants who on average performed more pumps on balloons also exploded more balloons across trials. Adjusted average pumps and explosions exhibited different patterns of correlations with the predictor variables, justifying the approach to retain both outcomes and perform separate 
analyses. Explosions was significantly correlated with gender $(r=.18$, males higher explosions), sensation seeking $(r=.20)$, BAS reward $(r=-.24)$ and BIS $(r=-.27)$ scores, while adjusted average pumps was significantly correlated with age $(r=.20)$ the spatial working memory and planning EF factor $(r=.24)$ and BIS scores $(r=-$ .21). The EF factors had few significant correlations with other variables, except for FSIQ being significantly correlated with the verbal inhibition and flexibility $(r=.43)$, spatial working memory and planning $(r=.41)$ and rule acquisition and switching $(r$ $=.34$ ) factors. However, poorer performance on the risky decision EF factor was significantly correlated with sensation seeking $(r=-.22)$.

\section{[INSERT TABLE 3 ABOUT HERE]}

\section{Adjusted Average Pumps}

The hierarchical regression for BART adjusted average pumps is summarized in Table 4. At step one of the hierarchical regression, age, sex and general intellectual ability accounted for a small but significant amount (i.e., $7.5 \%$ ) of the variance in adjusted average pumps, $F(3,125)=3.39, p<.01$, with age $(t=2.15, p<.05)$ a significant individual predictor.

Reward sensitivity self-report measures were entered at the second step, but failed to account for significant additional variance, $\Delta F(5,120)=1.56, p=.18$. The overall model remained significant, $F(8,120)=2.28, p>.05$, although age became a non-significant individual predictor $(t=2.00, p=.06)$.

At step three, the addition of the EF factors failed to account for significant additional variance compared to both the first, $\Delta F(10,115)=1.40, p=.19$, and 
second steps, $\Delta F(5,115)=1.23, p=.30$. The overall model at the third step remained significant, $F(13,115)=1.89, p>.05$, but with no significant individual predictors.

\section{[INSERT TABLE 4 ABOUT HERE]}

\section{Explosions}

The hierarchical regression for BART explosions is summarized in Table 5. At step one, the overall model was significant, $F(3,125)=2.97, p<.05$, accounting for $6.7 \%$ of the variance in BART explosion scores, although no variables emerged as significant individual predictors. The introduction of reward sensitivity measures at step two account for a significant amount of additional variance, $F(5,120)=3.30, p$ $<.01$ (the overall model at step two accounting for $17.9 \%$ of variance), with reward responsiveness $(t=-2.40, p<.01)$ emerging as a significant individual predictor. Greater reward responsiveness was associated with fewer explosions. At step three, the introduction of the EF factors did not account for a significant amount of additional variance in the model, $F(5,115)=0.18, p=.97$. The overall model remained significant, $F(13,115)=2.01, p<.05$, with BAS reward responsiveness remaining a significant individual predictor of BART explosions $(t=-2.17, p<.05)$.

\section{[INSERT TABLE 5 ABOUT HERE]}

Overall, the EF factors were not significantly predictive of risk-taking as measured by either BART adjusted average pumps or explosions when taking demographic and reward responsiveness factors into account. Age emerged as the only significant predictor in the first step of the regression model for BART adjusted average pumps, although the effect size was small. BAS reward responsiveness was 
the only significant predictor of BART explosions. Post-hoc power analyses were performed using the G*Power software (Faul, Erdfelder, Lang, \& Buchner, 2007) for both hierarchical regressions to confirm that sufficient participants numbers were available to detect significant effects. Adequate power (i.e., $\geq .80$ ) given the sample size of 129 participants was achieved for both the adjusted average pumps (power $=$ $.87)$ and explosions (power $=.93$ ) analyses.

\section{Discussion}

The aim of this research was to examine the developmental progression of EF task performance and its relation to risk-taking behavior under conditions of ambiguity during late adolescence and early adulthood in a typically developing sample of individuals aged 17 to 22 years. A battery of EF tasks was used to allow for assessment of a wide range of EF abilities, including measures of both cool and hot $\mathrm{EF}$, in a typically developing sample of individuals spanning later adolescence to early adulthood. Limited research has focused on examining potential developmental changes in EF that may continue into early adulthood, particularly in contexts that may pose additional regulatory challenges (i.e., "hot" contexts). Further, few studies have explicitly sought to test the key tenant of developmental imbalance models that greater risk-taking propensity is associated with weaker or immature EF during adolescence.

\section{Development of Executive Function}

In partial support of the first hypothesis, it was evident that for most EF measures there were no significant age effects on task performance. This suggests that at a performance-based level, EF was largely mature between the ages of 17 and 22 
years. This finding is consistent with a large body of evidence highlighting that most EFs are functionally mature by the time of early- to mid-adolescence (Huizinga et al., 2006; Lee et al., 2013). However, there were some exceptions to this general finding in relation to tasks measuring inhibitory control abilities. There were significant linear effects for verbal inhibition and switching errors on the color-word interference test, with errors continuing to decrease with increasing age for the sample studied. The color-word inhibition task assesses the ability to inhibit a prepotent and over-learned verbal response. There was also a significant linear decrease in stop signal reaction times with age, which taps the ability to inhibit an automatic motor response.

In relation to the development of inhibitory control, the current results can be compared with findings from other studies. For example, using stop signal, Stroop and Eriksen flankers tasks, Huizinga et al. (2006) produced evidence suggesting that inhibitory control reached adult levels between 11- and 15-years-old. However, somewhat consistent with the current study, they found that performance on the Stroop task (i.e., interference time) continued to improve into early adulthood. This may suggest that while inhibition may be functionally mature by the time of early- to mid-adolescence, slight improvements may continue into late adolescence and early adulthood. However, it cannot be discounted that the apparent improvements in inhibitory control could be accounted for by changes in processing speed across age (see, McAuley \& White, 2011; Span, Ridderinkhof, \& van der Molen, 2004), which were not controlled for in the current study.

Inconsistent with the second hypothesis proposing that developmental changes in hot EF would occur later than changes in cool EF tasks, no age-specific changes in hot EF task performance as measured by the CGT were evident from late adolescence to early adulthood. Performance on the CGT appeared to be equivalent across all 
ages, following the predominant developmental pattern of results for relatively cool EF tasks. On face value, this finding was not consistent with models of adolescent cognitive development hypothesizing that hot EF development continues into adolescence and occurs later than the maturation of cool EF (Zelazo \& Carlson, 2012)

Prencipe et al. (2011) found that performance on Iowa gambling and delay discounting tasks improved (i.e., advantageous responses and less impulsivity in the presence of potential reward) up until age 15 years. Taken with the current results, it is possible that the ability to effectively exert cognitive control under conditions of motivational and affective salience develops throughout early- to mid-adolescence to become functionally mature by late adolescence. In comparing the current results to those of Prencipe et al. (2011), who examined a younger sample group (i.e., 8-15 years), it is important to note that the current study examined an older sample group (i.e., 17-22 years). It is possible that the absence of a developmental effect for hot EF may have resulted from the examination of an older group, where the sample may have already largely developed the skills to implement cognitive control in situations posing additional motivational/affective regulatory challenges. This would be consistent the dual systems model proposed by Shulman et al. (2016), who argue that middle adolescents are most susceptible to their behavior being impacted by motivational/affective challenges, while later adolescents are better able to regulate their behavior.

It is also possible that the failure to detect a developmental effect of hot EF may have been due to the nature of the task used to measure the construct. A previous study using a gambling task paradigm derived from the CGT (i.e., Cake Gambling Task; van Leijenhorst, Westenberg, \& Crone, 2008) also failed to find any age-related 
effects in the pattern of risky decision-making for a sample of individuals aged 8 to 30 years. This is in contrast to the results of studies using the Iowa Gambling Task (IGT), which is widely used as a measure of affective decision-making. Results from studies using the IGT consistently highlight age-related changes in risky decisionmaking throughout adolescence, including that children and adolescents are less likely to consider long-term outcomes compared to adults, and that adolescents can be characterized as more approach oriented to reward and less avoidant of punishment relative to adults (Cauffman et al., 2010; Crone et al., 2016). It is possible that the lack of age-related differences for CGT-based measures compared to those found using the IGT is likely a function of differing task demands, with the IGT placing greater demands on working memory capacities (van Leijenhorst et al., 2008).

A criticism commonly levelled against risk decision-making tasks administered in laboratory settings is that they typically lack ecological validity by being unable to realistically simulate "real-world" conditions involving risky decision-making. It is possible that the gambling task did not effectively produce a strong-enough degree of motivational/affective significance in participants to elicit a hot EF effect within a controlled laboratory setting. The CGT does not provide any extrinsic reward to participants apart from accrual of "points" during the task, which may not have been sufficient to produce a context to meaningfully activate motivational/affective systems. Studies using gambling tasks have been found to produce inconsistent results in relation to whether adolescents are more susceptible to conditions involving risk-taking when compared to children and/or adults (e.g., Bjork \& Pardini, 2015; Defoe, Dubas, Figner, \& van Aken, 2015; Paulsen, Carter, Platt, Huettel, \& Brannon, 2011; van Leijenhorst et al., 2010). In conducting a metaanalysis of studies examining age differences in performance on risky decision- 
making tasks, Defoe et al. (2015) found that adolescents are not always the most susceptible age group to poor decision-making. Inconsistencies in study findings may suggest that the cognitive control system during adolescence is flexible and highly dependent on the motivational/affective salience of the context (Crone \& Dahl, 2012; Defoe et al., 2015; Li, 2017). It is possible that an effect of hot EF may be evident in older adolescent groups, but only where the context and/or task stimuli hold salience. For example, situations characterized by peer influence may be more effective in eliciting a salient motivational/affective context for the operation of hot EF processes (Albert, Chein, \& Steinberg, 2013).

In relation to age effects, the current results are consistent with a growing body of evidence indicating that EFs are largely mature by the time of early- to midadolescence, with little evidence of performance-based maturational changes into early adulthood. As noted by Romine and Reynolds (2005), it is difficult to establish whether the apparent slowing of EF maturation during adolescence actually reflects a slowing of the development of neurocognitive functions, or whether it is partly a function of the psychometric properties of measures. Current measures of EF may be insensitive to subtle age-related changes that continue occur throughout adolescence and into adulthood. This may be reflected in the presence of ceiling and floor effects in task performance, which were evident for the current sample. The measures used for the current study may have been unable to detect changes in EF that continue into early adulthood due to lacking sensitivity. More sensitive measures may be important in diagnostic settings to detect subclinical, but relevant variations in EF (e.g., emerging cognitive dysfunction in prodromal schizophrenia patients).

It is possible that the issue of EF measure sensitivity may partly explain the discrepancy between anatomical and functional/behavioral developmental 
neurocognitive findings. At an anatomical level, the protracted development of the PFC, which is believed to largely subserve EF, is consistently noted to continue throughout adolescence and into early adulthood. However, behavioral findings derived from cognitive tests do not consistently align with these physical changes, where EFs are typically "mature" by late childhood and early adolescence if examined solely from the perspective of test performance data. There is fMRI evidence to suggest that while adolescents can perform at mature/adult equivalent levels of functioning, this performance may require increased effortful attention, and stronger reliance on specific cortical regions such as the dorsolateral PFC (Luna, Padmanabhan, \& O'Hearn, 2010). Such results may be indicative of immaturities in the structure and function of the PFC, where adolescents may need to engage in more intensive and/or prolonged processing effort to perform at the same level as adults, generating more intensive cortical activity compared to the adult system (Luna et al., 2010).

\section{Risk Taking}

Findings relating to risk-taking and age were varied. The use of the BART as the primary risk-taking measure allowed for examination of the construct from the perspective of both positive (adjusted average pumps for unexploded balloons) and negative (balloon explosions) outcomes of risk-taking behavior under conditions of ambiguity. While there was no significant age effect of BART explosions, there was a significant age effect for adjusted average pumps, with a linear trend of increasing pumps (i.e., increasing risk-taking propensity) with increasing age. This suggests that risk-taking propensity may peak during early adulthood rather than late adolescence. Alternatively, this result may indicate that individuals are better able to engage in 
risk-taking under conditions of ambiguity "successfully" as they age to experience the positive rather than negative outcomes of such behavior.

It is notable that BART risk-taking (i.e., adjusted average pumps) exhibited a possible age effect, while CGT risk-taking did not, despite both outcomes being significantly correlated. It is possible that although these measures shared some overlap, the BART may have been more sensitive to possible age differences in risktaking propensity. In addition, the two measures may have tapped different aspects of risk-taking that varied in the timing of developmental maturity. The BART assesses risk-taking under conditions of ambiguity, which has been found to continue into early adulthood (Tymula et al., 2013), while the CGT measures decision-making under conditions of known risk, which is thought to mature earlier (Defoe et al., 2015).

It appeared that the current sample engaged in a high level of risk-taking as measured by the BART in comparison to the findings of Lejuez et al. (2002), who administered the task to a North American community-based sample of 86 males and females between the ages of 18- and 25-years. Using an independent samples $t$-test, the current Australian sample exhibited a significantly higher overall mean level of adjusted average pumps risk-taking $(M=36.46, S D=12.69)$ than the Lejuez et al. (2002) North American sample $(M=29.40, S D=13.00), t(213)=7.06, p<.001$. However, despite the similarity in age range, this comparison should be viewed with caution, given the potential of systematic differences between the two samples (e.g., nationality, socio-economic status) and differences in how the task was administered. The current finding of heightened levels of risk-taking for the Australian sample comprised of late adolescent and early adult individuals is consistent with evidence 
suggesting that risk-taking behaviors mostly peak during young adulthood (Willoughby et al., 2013).

\section{Risk Taking and Executive Functions}

Only limited support was found for the hypothesis derived from imbalance models that weaker cognitive control would be associated with a greater risk-taking propensity. Hierarchical regression results indicated that the EF factors derived from the measures failed to account for significant variance in risk-taking scores as measured by either BART adjusted average pumps or balloon explosions. Older age was the only variable to emerge as a significant predictor of greater BART adjusted average pumps (i.e., in the first stage of the hierarchical regression model), while reward responsiveness (measured by the BIS/BAS scale) was the only significant predictor of BART explosions. However, some bivariate level associations are worthy of note. First, the risky decision-making EF factor was significantly correlated with self-reported sensation seeking (i.e., greater risky decision-making associated with greater sensation seeking), which is consistent with imbalance model hypotheses. Second, the spatial working memory and planning EF factor was positively correlated with BART adjusted average pumps, although the association was not in the direction hypothesized by imbalance models. This finding suggests that better planning-related EF abilities may facilitate successful engagement in some risk-taking activities.

The failure to detect an association between EF and risk-taking in the expected direction for the current research likely due in-part to the composition and restricted age-range of the sample. Given the sample was drawn from an education community setting, it was less likely to have included individuals with pre-existing difficulties in EF. As argued by Bjork and Pardini (2015), risk-taking as a result of an imbalance 
between affective and control systems is likely specific to a subset of youth with disruptive behavior problems who present with EF deficits. It is more likely that the sample consisted of individuals with well-developed EF abilities (i.e., due to recruitment from a university setting) that assisted them in engaging in the risk-taking tasks. Consistent with this, the sample was characterized by well-developed and stable EF abilities. However, despite these well-developed and stable cognitive control abilities, the sample still engaged in a high level of risk-taking as measured by BART adjusted average pumps. This suggests that the presence of mature cognitive control abilities may not lead to reduced levels of engagement as predicted by imbalance models. Rather, mature cognitive control abilities may function as a protective factor against some of the negative outcomes linked to engagement in risk-taking. For example, mature cognitive control abilities may allow adolescents to employ more refined and sophisticated decision-making processes to plan and selectively engage in more considered risk-taking actions, and avoid more serious consequences attached to these behaviors (Baskin-Sommers, Waller, Fish, \& Hyde, 2015). In this manner, the risk-taking of older adolescents and early adults may become more regulated and less impulsive with maturing cognitive control abilities (Willoughby et al., 2013).

\section{Limitations}

The primary shortcoming of the research was that age effects were explored in the context of a cross-sectional design, and therefore cannot be considered a developmental analysis. As with all cross-sectional designs, it is possible that systematic differences existed across the age range that impacted task performance, therefore making comparisons across age difficult to interpret. Only longitudinal data is able to accurately characterize changes associated with maturation and 
development. There is a clear need for future studies to utilize longitudinal designs to more accurately characterize developmental changes in neuropsychological systems, and how these are linked to behavior.

Measurement and sample characteristics limited the capacity to fully test hypotheses and imbalance model predictions. First, there was only one measure of hot EF included in the assessment battery, and this may have contributed to the failure to detect an age effect. In comparison to cool EF, there are relatively fewer valid and reliable measures of hot EF available. Hot EF tasks tend to be constructed as decisionmaking tasks under conditions of risk (i.e., affective salience), including the Iowa Gambling Task (Bechara, Tranel, \& Damasio, 2000) and the cake gambling task (van Leijenhorst et al., 2008), for example. The measure of hot EF in the current study (i.e., the CGT) was designed as a decision-making and risk-taking task. In this regard it could be argued that the CGT and BART measured overlapping constructs and could both be conceptualized as either risk-taking or hot EF measures. However, only modest correlations were observed between the CGT outcome of risk-taking and the BART outcomes of adjusted average pumps $(r=.32)$ and explosions $(r=.35)$. This suggested they measures similar but not entirely overlapping constructs, the most obvious distinction being risk-taking under known (i.e., CGT) and ambiguous (i.e., BART) conditions.

Second, the sample spanned a narrow age-range in an attempt to examine risktaking at an age that it is commonly identified to peak. A wider age range and longitudinal cohort starting in childhood and extending into adulthood would be necessary to fully examine the major predictions made by imbalance models. It is possible that the age-range of 17 - to 22 -years-old may have represented a narrow period of development where the traits examined (i.e., EF and risk-taking) were 
relatively stable, and/or there was limited variation across individuals, resulting in difficulties in detecting effects. It is possible that the age range of the sample may have represented a developmental period where engagement in risk-taking was relatively elevated and widespread (i.e., a "normative" peak), creating a ceiling effect and masking longer-standing individual differences in risk-taking that may persist into adulthood. Finally, the current study lacked the inclusion of a clinical sample that would be necessary to test whether deficits in EF are linked to risk-taking behavior for a subgroup of individuals with histories of behavioral and impulse control problems.

In summary, the results of the current study were consistent with existing research highlighting that EF abilities are largely mature by the time of midadolescence, with only minor age-related changes in verbal inhibition ability continuing into later adolescence and early adulthood. Unexpectedly, no age-related effects for hot EF performance were detected, despite adolescence being theorized as a period of sensitivity of reward processing. Additionally, no support was found for the imbalance model prediction that lower/weaker levels of cognitive control, as measured by EF tasks, would be associated with a greater risk-taking propensity. The research adds to an emerging body of findings that suggest risk-taking in healthy adolescents is developmentally normative and not a result of immaturity in cognitive functioning, but rather may be facilitated by in-tact and functional cognitive control abilities.

\section{Conflict of interest: None.}

Funding: JO was awarded an Australian Postgraduate Scholarship to support the completion of this research. 
Ethical standards: The authors assert that all procedures contributing to this work comply with the ethical standards of the relevant national and institutional committees on human experimentation, and with the Helsinki Declaration of 1975, as revised in 2008.

Data sharing: The data for this research are made available on the Open Science Framework: https://osf.io/sq2xe/ 


\section{References}

Aklin, W. M., Lejuez, C. W., Zvolensky, M. J., Kahler, C. W., \& Gwadz, M. (2005). Evaluation of Behavioral Measures of Risk Taking Propensity with Inner City Adolescents. Behaviour Research and Therapy, 43(2), 215-228. doi:10.1016/j.brat.2003.12.007

Albert, D., Chein, J., \& Steinberg, L. (2013). The teenage brain: Peer influences on adolescent decision making. Current Directions in Psychological Science, 22(2), 114-120. doi:10.1177/0963721412471347

Baskin-Sommers, A. R., Waller, R., Fish, A. M., \& Hyde, L. W. (2015). Callousunemotional traits trajectories interact with earlier conduct problems and executive control to predict violence and substance use among high risk male adolescents. Journal of Abnormal Child Psychology, 43(8), 1529-1541. doi:10.1007/s10802-015-0041-8

Bechara, A., Damasio, H., Tranel, D., \& Anderson, S. W. (1998). Dissociation of working memory from decision making within the human prefrontal cortex. The Journal of Neuroscience, 18(1), 428-437.

Bechara, A., Tranel, D., \& Damasio, H. (2000). Characterization of the decisionmaking deficit of patients with ventromedial prefrontal cortex lesions. Brain, 123(11), 2189-2202. doi:10.1093/brain/123.11.2189\%J Brain

Best, J. R., \& Miller, P. H. (2010). A developmental perspective on executive function. Child Development, 81(6), 1641-1660. doi:10.1111/j.14678624.2010.01499.x

Bjork, J. M., \& Pardini, D. A. (2015). Who are those "risk-taking adolescents"? Individual differences in developmental neuroimaging research. Dev Cogn Neurosci, 11, 56-64. doi:10.1016/j.den.2014.07.008

Blair, M. A., Moyett, A., Bato, A. A., DeRosse, P., \& Karlsgodt, K. H. (2018). The Role of Executive Function in Adolescent Adaptive Risk-Taking on the Balloon Analogue Risk Task. Developmental Neuropsychology, 43(7), 566580. doi:10.1080/87565641.2018.1510500

Blankenstein, N. E., Schreuders, E., Peper, J. S., Crone, E. A., \& van Duijvenvoorde, A. C. K. (2018). Individual differences in risk-taking tendencies modulate the neural processing of risky and ambiguous decision-making in adolescence. NeuroImage, 172, 663-673. doi:10.1016/j.neuroimage.2018.01.085

Brocki, K. C., \& Bohlin, G. (2004). Executive functions in children aged 6 to 13: A dimensional and developmental study. Developmental Neuropsychology, 26(2), 571-593. doi:10.1207/s15326942dn2602_3

Caballero, A., Granberg, R., \& Tseng, K. Y. (2016). Mechanisms contributing to prefrontal cortex maturation during adolescence. Neuroscience and Biobehavioral Reviews, 70, 4-12. doi:10.1016/j.neubiorev.2016.05.013

Carver, C. S., \& White, T. L. (1994). Behavioral Inhibition, Behavioral Activation, and Affective Responses to Impending Reward and Punishment: The BIS/BAS Scales. Journal of Personality and Social Psychology, 67(2), 319333. doi:10.1037/0022-3514.67.2.319

Casey, B. J., Getz, S., \& Galván, A. (2008). The adolescent brain. Developmental Review, 28(1), 62-77.

Cauffman, E., Shulman, E. P., Steinberg, L., Claus, E., Banich, M. T., Graham, S., \& Woolard, J. (2010). Age differences in affective decision making as indexed by performance on the Iowa Gambling Task. Developmental Psychology, 46(1), 193-207. doi:10.1037/a0016128 
Crone, E. A., \& Dahl, R. E. (2012). Understanding adolescence as a period of socialaffective engagement and goal flexibility. Nature Reviews Neuroscience, 13(9), 636-650. doi:10.1038/nrn3313

Crone, E. A., van Duijvenvoorde, A. C., \& Peper, J. S. (2016). Annual Research Review: Neural contributions to risk-taking in adolescence--developmental changes and individual differences. Journal of Child Psychology and Psychiatry, 57(3), 353-368. doi:10.1111/jcpp.12502

Crowley, T. J., Dalwani, M. S., Mikulich-Gilbertson, S. K., Du, Y. P., Lejuez, C. W., Raymond, K. M., \& Banich, M. T. (2010). Risky decisions and their consequences: neural processing by boys with Antisocial Substance Disorder. PLoS One, 5(9), e12835. doi:10.1371/journal.pone.0012835

Defoe, I. N., Dubas, J. S., Figner, B., \& van Aken, M. A. (2015). A meta-analysis on age differences in risky decision making: adolescents versus children and adults. Psychological Bulletin, 141(1), 48-84. doi:10.1037/a0038088

Delis, D., Kaplan, E., \& Kramer, N. (2001). Delis-Kaplan executive function system. Odessa, FL: Psychological Assessment Resources.

DeLisi, M., \& Piquero, A. R. (2011). New frontiers in criminal careers research, 2000-2011: A state-of-the-art review. Journal of Criminal Justice, 39(4), 289301. doi:10.1016/j.jcrimjus.2011.05.001

Duell, N., Steinberg, L., Chein, J., Al-Hassan, S. M., Bacchini, D., Lei, C., . . . Alampay, L. P. (2016). Interaction of reward seeking and self-regulation in the prediction of risk taking: A cross-national test of the dual systems model. Dev Psychol, 52(10), 1593-1605. doi:10.1037/dev0000152

Ernst, M. (2014). The triadic model perspective for the study of adolescent motivated behavior. Brain Cogn, 89, 104-111. doi:10.1016/j.bandc.2014.01.006

Ernst, M., \& Paulus, M. P. (2005). Neurobiology of decision making: a selective review from a neurocognitive and clinical perspective. Biological Psychiatry, 58(8), 597-604. doi:10.1016/j.biopsych.2005.06.004

Faul, F., Erdfelder, E., Lang, A. G., \& Buchner, A. (2007). G*Power 3: A flexible statistical power analysis for the social, behavioral and biomedical sciences. Behavior Research Methods, 39(2), 175-191. Retrieved from https://www.ncbi.nlm.nih.gov/pubmed/17695343

Friedman, N. P., \& Miyake, A. (2017). Unity and diversity of executive functions: Individual differences as a window on cognitive structure. Cortex, 86, 186204. doi:10.1016/j.cortex.2016.04.023

Giedd, J. N. (2004). Structural magnetic resonance imaging of the adolescent brain. Annals of the New York Academy of Sciences, 1021, 77-85. doi:10.1196/annals.1308.009

Huizinga, M., Dolan, C. V., \& van der Molen, M. W. (2006). Age-related change in executive function: Developmental trends and a latent variable analysis. Neuropsychologia, 44(11), 2017-2036. doi:10.1016/j.neuropsychologia.2006.01.010

Lee, K., Bull, R., \& Ho, R. M. (2013). Developmental changes in executive functioning. Child Development, 84(6), 1933-1953. doi:10.1111/cdev.12096

Lejuez, C. W., Aklin, W. M., Zvolensky, M. J., \& Pedulla, C. M. (2003). Evaluation of the Balloon Analogue Risk Task (BART) as a Predictor of Adolescent Real-World Risk-Taking Behaviours. Journal of Adolescence, 26(4), 475-479. doi:10.1016/S0140-1971(03)00036-8

Lejuez, C. W., Read, J. P., Kahler, C. W., Richards, J. B., Ramsey, S. E., Stuart, G. L., . . Brown, R. A. (2002). Evaluation of a Behavioral Measure of Risk 
Taking: The Balloon Analogue Risk Task (BART). Journal of Experimental Psychology: Applied, 8(2), 75-84.

Li, R. (2017). Flexing dual-systems models: How variable cognitive control in children informs our understanding of risk-taking across development. Dev Cogn Neurosci, 27, 91-98. doi:10.1016/j.den.2017.08.007

Luna, B., Garver, K. E., Urban, T. A., Lazar, N. A., \& Sweeney, J. A. (2004). Maturation of cognitive processes from late childhood to adulthood. Child Development, 75(5), 1357-1372. doi:10.1111/j.1467-8624.2004.00745.x

Luna, B., Padmanabhan, A., \& O'Hearn, K. (2010). What has fMRI told us about the development of cognitive control through adolescence? Brain and Cognition, 72, 101-113.

MacPherson, L., Magidson, J. F., Reynolds, E. K., Kahler, C. W., \& Lejuez, C. W. (2010). Changes in sensation seeking and risk-taking propensity predict increases in alcohol use among early adolescents. Alcoholism: Clinical and Experimental Research, 34(8), 1400-1408. doi:10.1111/j.15300277.2010.01223.x

Mamerow, L., Frey, R., \& Mata, R. (2016). Risk taking across the life span: A comparison of self-report and behavioral measures of risk taking. Psychol Aging, 31(7), 711-723. doi:10.1037/pag0000124

McAuley, T., \& White, D. A. (2011). A latent variables examination of processing speed, response inhibition, and working memory during typical development. J Exp Child Psychol, 108(3), 453-468. doi:10.1016/j.jecp.2010.08.009

McDonald, R. P. (1999). Test theory: A unified treatment. New York: Psychology Press.

Miyake, A., \& Friedman, N. P. (2012). The nature and organization of individual differences in executive functions: Four general conclusions. Current Directions in Psychological Science, 21(1), 8-15. doi:10.1177/0963721411429458

Morgan, J. E., Bowen, K. L., Moore, S. C., \& van Goozen, S. H. M. (2014). The relationship between reward and punishment sensitivity and antisocial behavior in male adolescents. Personality and Individual Differences, 63, 122127. doi:10.1016/j.paid.2014.01.054

Paulsen, D. J., Carter, R. M., Platt, M. L., Huettel, S. A., \& Brannon, E. M. (2011). Neurocognitive development of risk aversion from early childhood to adulthood. Frontiers in Human Neuroscience, 5, 178. doi:10.3389/fnhum.2011.00178

Prencipe, A., Kesek, A., Cohen, J., Lamm, C., Lewis, M. D., \& Zelazo, P. D. (2011). Development of hot and cool executive function during the transition to adolescence. J Exp Child Psychol, 108(3), 621-637. doi:10.1016/j.jecp.2010.09.008

Psychological Corporation. (1999). Wechsler abbreviated scale of intelligence. San Antonio, TX: Pearson.

R Core Team. (2019). R: A language for statistical computing. Vienna, Austria: R Foundation for Statistical Computing. Retrieved from https://www.Rproject.org/

Revelle, W. (2017). psych: Procedures for personality and psychological research (Version 1.7.5). Evanston, Illinois, USA: Northwestern University. Retrieved from https://CRAN.R-project.org/package=psych

Reynolds, B. W., Basso, M. R., Miller, A. K., Whiteside, D. M., \& Combs, D. (2019). Executive function, impulsivity, and risky behaviors in young adults. 
Neuropsychology, 33(2), 212-221. doi:10.1037/neu0000510

Romer, D., Betancourt, L. M., Brodsky, N. L., Giannetta, J. M., Yang, W., \& Hurt, H. (2011). Does adolescent risk taking imply weak executive function? A prospective study of relations between working memory performance, impulsivity, and risk taking in early adolescence. Developmental Science, 14(5), 1119-1133. doi:10.1111/j.1467-7687.2011.01061.x

Romer, D., Reyna, V. F., \& Satterthwaite, T. D. (2017). Beyond stereotypes of adolescent risk taking: Placing the adolescent brain in developmental context. Dev Cogn Neurosci, 27, 19-34. doi:10.1016/j.den.2017.07.007

Romine, C. B., \& Reynolds, C. R. (2005). A model of the development of frontal lobe functioning: findings from a meta-analysis. Appl Neuropsychol, 12(4), 190201. doi:10.1207/s15324826an1204 2

Schafer, J. L. (1999). Multiple imputation: A primer. Statistical Methods in Medical Research, 8(1), 3-15. doi:10.1177/096228029900800102

Shulman, E. P., Smith, A. R., Silva, K., Icenogle, G., Duell, N., Chein, J., \& Steinberg, L. (2016). The dual systems model: Review, reappraisal, and reaffirmation. Dev Cogn Neurosci, 17, 103-117. doi:10.1016/j.den.2015.12.010

Span, M. M., Ridderinkhof, K. R., \& van der Molen, M. W. (2004). Age-related changes in the efficiency of cognitive processing across the life span. Acta Psychologica, 117(2), 155-183. doi:10.1016/j.actpsy.2004.05.005

Steinberg, L. (2004). Risk Taking in Adolescence: What Changes, and Why? Annals of the New York Academy of Sciences, 1021, 51-58.

Steinberg, L. (2008). A social neuroscience perspective on adolescent risk-taking. Developmental Review, 28(1), 1-29. doi:10.1016/j.dr.2007.08.002

Steinberg, L., Albert, D., Cauffman, E., Banich, M., Graham, S., \& Woolard, J. (2008). Age differences in sensation seeking and impulsivity as indexed by behavior and self-report: Evidence from a dual systems model. Developmental Psychology, 44(6), 1764-1778. doi:10.1037/a0012955

Steinberg, L., Icenogle, G., Shulman, E. P., Breiner, K., Chein, J., Bacchini, D., . . . Takash, H. M. S. (2018). Around the world, adolescence is a time of heightened sensation seeking and immature self-regulation. Developmental Science, 21(2), e12532. doi:10.1111/desc.12532

Stroop, J. R. (1935). Studies of interference in serial verbal reactions. Journal of Experimental Psychology, 18(6), 643-662. doi:DOI 10.1037/h0054651

Tabachnick, B. G., \& Fidell, L. S. (2014). Using multivariate statistics (Sixth ed.). London: Pearson.

The National Health and Medical Research Council. (2015). National Statement on Ethical Conduct in Human Research 2007. Canberra: Commonwealth of Australia

Tymula, A., Rosenberg Belmaker, L. A., Ruderman, L., Glimcher, P. W., \& Levy, I. (2013). Like cognitive function, decision making across the life span shows profound age-related changes. Proceedings of the National Academy of Sciences, 110(42), 17143. doi:10.1073/pnas.1309909110

van Buuren, S., \& Groothuis-Oudshoorn, K. (2011). mice: Multivariate Imputation by Chained Equations in R. Journal of Statistical Software, 45(3), 1-67. Retrieved from http://www.jstatsoft.org/v45/i03/

van Leijenhorst, L., Gunther Moor, B., Op de Macks, Z. A., Rombouts, S. A., Westenberg, P. M., \& Crone, E. A. (2010). Adolescent risky decision-making: Neurocognitive development of reward and control regions. NeuroImage, 
51(1), 345-355. doi:10.1016/j.neuroimage.2010.02.038

van Leijenhorst, L., Westenberg, P. M., \& Crone, E. A. (2008). A developmental study of risky decisions on the cake gambling task: Age and gender analyses of probability estimation and reward evaluation. Developmental Neuropsychology, 33(2), 179-196. doi:10.1080/87565640701884287

Willoughby, T., Good, M., Adachi, P. J., Hamza, C., \& Tavernier, R. (2013). Examining the link between adolescent brain development and risk taking from a social-developmental perspective. Brain and Cognition, 83(3), 315323. doi:10.1016/j.bandc.2013.09.008

Wood, S. N. (2011). Fast stable restricted maximum likelihood and marginal likelihood estimation of semiparametric generalized linear models. Journal of the Royal Statistical Society: Series B (Statistical Methodology), 73(1), 3-36. doi:10.1111/j.1467-9868.2010.00749.x

Zelazo, P. D., \& Carlson, S. M. (2012). Hot and cool executive function in childhood and adolescence: Development and plasticity. Child Development Perspectives, 6(4), 354-360. doi:10.1111/j.1750-8606.2012.00246.x

Zelazo, P. D., Craik, F. I., \& Booth, L. (2004). Executive function across the life span. Acta Psychologica, 115(2-3), 167-183. doi:10.1016/j.actpsy.2003.12.005

Zuckerman, M., Eysenck, S., \& Eysenck, H. J. (1978). Sensation seeking in England and America: Cross-cultural, age, and sex comparisons. Journal of Consulting and Clinical Psychology, 46(1), 139-149. doi:10.1037/0022-006X.46.1.139 
Table 1.

Means and standard deviations for executive function and risk-taking task performance and reward sensitivity self-report measures.

\begin{tabular}{|c|c|c|c|c|c|c|c|}
\hline \multirow[t]{2}{*}{ Task } & \multicolumn{2}{|c|}{ Male } & \multicolumn{2}{|c|}{ Female } & \multicolumn{2}{|c|}{ Total } & \multirow[t]{2}{*}{ Age $^{1}$} \\
\hline & Mean & SD & Mean & $\mathrm{SD}$ & Mean & $\mathrm{SD}$ & \\
\hline \multicolumn{8}{|l|}{ Trail-making } \\
\hline Switching time & 60.61 & 19.82 & 59.55 & 21.54 & 60.06 & 20.66 & $n s$ \\
\hline Switching errors & 1.00 & 1.15 & 0.69 & 1.00 & 0.84 & 1.08 & $n s$ \\
\hline \multicolumn{8}{|l|}{ Verbal fluency } \\
\hline Total letter & 39.90 & 11.09 & 42.13 & 11.25 & 41.06 & 11.18 & $n s$ \\
\hline Total category & 46.35 & 8.34 & 46.69 & 9.10 & 46.53 & 8.71 & $n s$ \\
\hline Total switching & 14.35 & 2.70 & 15.57 & 2.81 & 14.98 & 2.81 & $n s$ \\
\hline Total errors & 3.00 & 2.50 & 2.49 & 1.96 & 2.74 & 2.24 & $n s$ \\
\hline \multicolumn{8}{|l|}{ Color-word inhibition } \\
\hline Inhibition time & 43.21 & 9.42 & 46.10 & 8.76 & 44.71 & 9.17 & $n s$ \\
\hline Switching time & 53.94 & 10.14 & 55.09 & 11.63 & 54.53 & 10.91 & $n s$ \\
\hline Inhibition errors & 2.27 & 1.87 & 1.94 & 1.75 & 2.10 & 1.81 & $F(1.00)=7.60^{* *}, R_{a d j}^{2}=.05$ \\
\hline Switching errors & 3.00 & 2.54 & 2.79 & 2.29 & 2.89 & 2.40 & $F(1.00)=8.97 * *, R_{a d j}^{2}=.06$ \\
\hline \multicolumn{8}{|l|}{ Tower } \\
\hline Correct & 8.50 & 0.74 & 8.39 & 1.00 & 8.44 & 0.88 & $n s$ \\
\hline Achievement score & 17.84 & 3.13 & 17.67 & 3.14 & 17.75 & 3.12 & $n s$ \\
\hline Violations & 0.55 & 0.88 & 0.67 & 1.24 & 0.61 & 1.08 & $n s$ \\
\hline \multicolumn{8}{|l|}{ Cambridge Gambling } \\
\hline Delay aversion & 0.20 & 0.15 & 0.22 & 0.18 & 0.21 & 0.17 & $n s$ \\
\hline Deliberation time (milliseconds) & 1809.59 & 622.71 & 1916.01 & 567.12 & 1864.86 & 594.55 & $n s$ \\
\hline Overall proportion bet & 0.55 & 0.13 & 0.52 & 0.11 & 0.54 & 0.12 & $n s$ \\
\hline Quality of decision-making & 0.93 & 0.09 & 0.95 & 0.09 & 0.94 & 0.09 & $n s$ \\
\hline Risk adjustment & 1.43 & 0.93 & 1.33 & 1.01 & 1.38 & 0.97 & $n s$ \\
\hline Risk taking & 0.60 & 0.13 & 0.55 & 0.11 & 0.57 & 0.12 & $n s$ \\
\hline \multicolumn{8}{|l|}{ Intra/extradimensional set shift } \\
\hline Stages completed & 8.76 & 0.64 & 8.60 & 0.80 & 8.67 & 0.73 & $n s$ \\
\hline Total errors adjusted & 18.82 & 17.32 & 22.33 & 18.63 & 20.64 & 18.03 & $n s$ \\
\hline \multicolumn{8}{|l|}{ Stop signal task } \\
\hline Direction errors & 4.06 & 5.04 & 3.75 & 3.72 & 3.90 & 4.39 & $n s$ \\
\hline Proportion successful stops & 0.48 & 0.06 & 0.50 & 0.05 & 0.49 & 0.06 & $n s$ \\
\hline Median correct reaction time on & 361.24 & 87.50 & 363.54 & 60.51 & 362.44 & 74.42 & $n s$ \\
\hline
\end{tabular}




\begin{tabular}{|c|c|c|c|c|c|c|c|}
\hline go trials (milliseconds) & & & & & & & \\
\hline $\begin{array}{l}\text { Stop signal reaction time } \\
\text { (milliseconds) }\end{array}$ & 163.97 & 46.12 & 162.91 & 39.74 & 163.42 & 42.76 & $F(1.00)=4.53^{*}, R_{a d j}^{2}=.03$ \\
\hline \multicolumn{8}{|l|}{ Spatial working memory } \\
\hline Strategy score & 26.35 & 5.63 & 27.63 & 6.54 & 27.02 & 6.13 & $n s$ \\
\hline Total errors & 9.31 & 9.32 & 13.67 & 12.79 & 11.57 & 11.42 & $n s$ \\
\hline \multicolumn{8}{|l|}{ Risk taking } \\
\hline BART adjusted average pumps & 37.54 & 13.61 & 34.15 & 10.34 & 35.78 & 12.09 & $F(2.85)=3.25^{*}, R_{a d j}^{2}=.07$ \\
\hline Explosions & 9.69 & 4.29 & 8.24 & 3.53 & 8.94 & 3.96 & $n s$ \\
\hline \multicolumn{8}{|l|}{ Reward sensitivity } \\
\hline Sensation seeking & 3.60 & 1.74 & 3.46 & 1.87 & 3.53 & 1.80 & $n s$ \\
\hline BAS drive & 10.47 & 2.54 & 11.06 & 2.16 & 10.78 & 2.36 & $n s$ \\
\hline BAS fun & 11.50 & 2.36 & 11.94 & 2.21 & 11.73 & 2.29 & $n s$ \\
\hline BAS reward & 16.24 & 2.39 & 17.43 & 2.00 & 16.86 & 2.27 & $n s$ \\
\hline BIS & 19.65 & 3.39 & 22.47 & 3.15 & 21.10 & 3.55 & $n s$ \\
\hline
\end{tabular}

Notes. $* p<.05, * * p<.01, * * * p<.001$.

${ }^{1}$ Age effects on task outcomes examined using generalized additive models to allow for possible non-linear effects. Significant effects for smooth terms reported as: $F$ (effective degrees of freedom), adjusted $R^{2}$ 
Table 2

Factor loadings, communalities, errors, and proportions of variance for the final fivefactor exploratory factor analysis model for executive function measures

\begin{tabular}{lccccccc}
\hline & & & & Factor $^{\dagger}$ & & & \\
Outcome & One & Two & Three & Four & Five & $h^{2}$ & $u^{2}$ \\
\hline Trail-making time & 0.43 & 0.08 & 0.08 & 0.06 & -0.05 & 0.24 & 0.76 \\
Verbal fluency letter & 0.46 & 0.23 & 0.11 & -0.08 & 0.07 & 0.34 & 0.66 \\
Verbal fluency category & 0.56 & 0.15 & 0.06 & 0.03 & 0.03 & 0.39 & 0.61 \\
Verbal fluency switching & 0.68 & 0.02 & 0.02 & 0.02 & -0.03 & 0.47 & 0.53 \\
Color-word inhibition time & 0.61 & 0.00 & -0.06 & 0.01 & 0.03 & 0.36 & 0.64 \\
Color-word switching time & 0.76 & -0.11 & -0.03 & 0.02 & -0.03 & 0.55 & 0.45 \\
SWM strategy score & -0.03 & 0.73 & 0.07 & 0.07 & -0.03 & 0.57 & 0.43 \\
SWM total errors & 0.03 & 0.91 & -0.04 & -0.06 & 0.02 & 0.81 & 0.19 \\
Tower total correct & 0.12 & 0.33 & 0.19 & -0.02 & 0.02 & 0.20 & 0.80 \\
Tower achievement score & 0.20 & 0.40 & 0.02 & 0.06 & 0.02 & 0.25 & 0.75 \\
IED stages completed & 0.01 & -0.04 & 0.93 & -0.04 & -0.05 & 0.86 & 0.14 \\
IED adjusted errors & 0.00 & 0.02 & 0.96 & 0.02 & 0.04 & 0.94 & 0.06 \\
CGT delay aversion & -0.09 & 0.27 & 0.13 & 0.32 & -0.03 & 0.22 & 0.78 \\
CGT deliberation time & -0.01 & -0.18 & 0.07 & -0.50 & 0.14 & 0.33 & 0.67 \\
CGT decision-making & 0.02 & -0.05 & -0.01 & 1.08 & 0.02 & 1.15 & -0.15 \\
CGT risk-adjustment & 0.11 & -0.30 & -0.12 & -0.46 & 0.05 & 0.36 & 0.64 \\
SST direction errors & -0.01 & 0.02 & 0.01 & 0.01 & 0.98 & 0.96 & 0.04 \\
SST median correct RT & -0.05 & -0.20 & 0.07 & 0.03 & 0.51 & 0.31 & 0.69 \\
SST SSRT & 0.02 & 0.04 & -0.09 & -0.03 & 0.62 & 0.39 & 0.61 \\
\multicolumn{1}{c}{ Proportion variance } & .12 & .11 & .10 & .09 & .09 & & \\
\hline Salist & & & & & &
\end{tabular}

Salient structure loadings for variables within factors are shaded to aid interpretation.

$h^{2}=$ Communality or common variance; $u^{2}=$ error or unique variance.

†Factor labels:

One - Verbal inhibition and flexibility

Two - Spatial working memory and planning

Three - Rule acquisition and switching

Four - Risky decision-making

Five - Motor inhibition 
Table 3

Correlations (Pearson's r) among age, sex, general intelligence, reward sensitivity, executive function factors and risk-taking variables included in the hierarchical regression $(N=129)$.

\begin{tabular}{|c|c|c|c|c|c|c|c|c|c|c|c|c|c|c|}
\hline 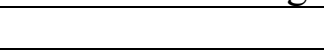 & 1 & 2 & 3 & 4 & 5 & 6 & 7 & 8 & 9 & 10 & 11 & 12 & 13 & 14 \\
\hline \multicolumn{15}{|l|}{ 1. Age } \\
\hline 2. Gender & .03 & & & & & & & & & & & & & \\
\hline 3. WASI FSIQ & .05 & .09 & & & & & & & & & & & & \\
\hline 4. Sensation seeking & -.02 & .04 & -.08 & & & & & & & & & & & \\
\hline 5. BAS drive & -.02 & -.13 & -.04 & $.33 * * *$ & & & & & & & & & & \\
\hline 6. BAS fun & .02 & -.10 & -.14 & $.65^{* * *}$ & $.50 * * *$ & & & & & & & & & \\
\hline 7. BAS reward & -.02 & $-.26 * *$ & -.15 & $.19 *$ & $.25^{* *}$ & $.41 * * *$ & & & & & & & & \\
\hline 8. BIS & $-.17^{*}$ & $-.40 * * *$ & -.04 & -.13 & -.09 & -.09 & $.23^{* *}$ & & & & & & & \\
\hline 9. Verbal EF & -.06 & -.04 & $.43 * * *$ & -.03 & .03 & -.01 & -.01 & -.03 & & & & & & \\
\hline 10. Spatial EF & .04 & $.17^{*}$ & $.41 * * *$ & .07 & .09 & .01 & -.10 & -.05 & $.20^{*}$ & & & & & \\
\hline 11. Rule EF & .07 & .10 & $.34 * * *$ & .09 & .11 & .04 & .12 & .03 & .11 & $.24 * *$ & & & & \\
\hline 12. Risky EF & -.03 & -.13 & .16 & $-.22 *$ & -.08 & -.16 & -.01 & .12 & .09 & .13 & .01 & & & \\
\hline 13. Motor EF & .15 & -.06 & .01 & .04 & .01 & -.06 & .12 & -.10 & -.06 & -.04 & -.03 & -.04 & & \\
\hline 14. BART pumps & $.20 *$ & .14 & .16 & .13 & -.06 & .03 & -.17 & $-.21 *$ & -.03 & $.24 * *$ & .11 & .04 & -.02 & \\
\hline 15. BART explosions & .13 & $.18^{*}$ & .15 & $.20 *$ & .01 & .09 & $-.24 * *$ & $-.27 * *$ & .02 & .17 & .04 & -.06 & .00 & $.91 * * *$ \\
\hline
\end{tabular}

Notes. $* p<.05, * * p<.01, * * * p<.001$. BART $=$ Balloon analogue risk task; BAS = Behavioral activation scale; BIS $=$ Behavioral inhibition scale; CGT $=$ Cambridge gambling task; $\mathrm{EF}=$ Executive function; IED = Intra/extradimensional shift task; SWM = Spatial working memory; WASI FSIQ = Wechsler abbreviated scales of intelligence full scale intelligence quotient. 
Table 4.

Hierarchical regression results for executive function measures predicting BART adjusted average pumps $(N=129)$.

\begin{tabular}{|c|c|c|c|c|c|c|c|c|c|c|c|c|c|c|c|}
\hline \multirow[b]{2}{*}{ Variable } & \multicolumn{5}{|c|}{$\begin{array}{c}\text { Step One } \\
\text { Demographics }\end{array}$} & \multicolumn{5}{|c|}{$\begin{array}{c}\text { Step Two } \\
\text { Reward sensitivity }\end{array}$} & \multicolumn{5}{|c|}{$\begin{array}{c}\text { Step three } \\
\text { Executive function }\end{array}$} \\
\hline & $B$ & $S E B$ & $\beta$ & $s r$ & $t$ & $B$ & $S E B$ & $\beta$ & $s r$ & $t$ & $B$ & $S E B$ & $\beta$ & $s r$ & $t$ \\
\hline Age & 1.37 & 0.64 & 2.24 & .18 & $2.15^{*}$ & 1.22 & 0.64 & 2.00 & .16 & 1.90 & 1.13 & 0.65 & 1.84 & .15 & 1.73 \\
\hline Sex & 2.97 & 2.08 & 2.97 & .12 & 1.43 & 0.67 & 2.32 & 0.66 & .02 & 0.29 & -0.42 & 2.40 & -0.42 & -.01 & -0.18 \\
\hline FSIQ & 0.16 & 0.10 & 1.67 & .14 & 1.60 & 0.16 & 0.10 & 1.65 & .13 & 1.57 & 0.09 & 0.13 & 0.96 & .06 & 0.73 \\
\hline Sensation seeking & & & & & & 1.04 & 0.76 & 1.88 & .12 & 1.37 & 0.99 & 0.78 & 1.78 & .11 & 1.27 \\
\hline BAS drive & & & & & & -0.50 & 0.51 & -1.18 & -.08 & -0.98 & -0.63 & 0.51 & -1.49 & -.10 & -1.23 \\
\hline BAS fun & & & & & & 0.23 & 0.69 & 0.53 & .03 & 0.33 & 0.23 & 0.71 & 0.52 & .03 & 0.32 \\
\hline BAS reward & & & & & & -0.71 & 0.53 & -1.62 & -.11 & -1.35 & -0.66 & 0.55 & -1.49 & -.10 & -1.19 \\
\hline BIS & & & & & & -0.40 & 0.34 & -1.42 & -.10 & -1.19 & -0.52 & 0.34 & -1.84 & -.13 & -1.52 \\
\hline Verbal EF & & & & & & & & & & & -1.23 & 1.15 & -1.23 & -.09 & -1.07 \\
\hline Spatial EF & & & & & & & & & & & 2.23 & 1.17 & 2.23 & .16 & 1.90 \\
\hline Rule EF & & & & & & & & & & & 0.69 & 1.14 & 0.69 & .05 & 0.60 \\
\hline Risky EF & & & & & & & & & & & 0.66 & 1.08 & 0.66 & .05 & 0.61 \\
\hline Motor EF & & & & & & & & & & & -0.44 & 1.08 & -0.44 & -.03 & -0.41 \\
\hline$R^{2}$ & & & & & .08 & & & & & .13 & & & & & .18 \\
\hline$F$ model & & & & & $3.39 *$ & & & & & $2.28 *$ & & & & & $1.89^{*}$ \\
\hline$(d f)$ & & & & & $(3,125)$ & & & & & $(8,120)$ & & & & & $(13,115)$ \\
\hline$\Delta F$ & & & & & -- & & & & & 1.56 & & & & & 1.23 \\
\hline$(d f)$ & & & & & & & & & & $(5,120)$ & & & & & $(5,115)$ \\
\hline
\end{tabular}


Table 5.

Hierarchical regression results for executive function measures predicting BART explosions $(N=129)$.

\begin{tabular}{|c|c|c|c|c|c|c|c|c|c|c|c|c|c|c|c|}
\hline \multirow[b]{2}{*}{ Variable } & \multicolumn{5}{|c|}{$\begin{array}{c}\text { Step One } \\
\text { Demographics }\end{array}$} & \multicolumn{5}{|c|}{$\begin{array}{c}\text { Step Two } \\
\text { Reward sensitivity }\end{array}$} & \multicolumn{5}{|c|}{$\begin{array}{c}\text { Step three } \\
\text { Executive function }\end{array}$} \\
\hline & $B$ & $S E B$ & $\beta$ & $s r$ & $t$ & $B$ & $S E B$ & $\beta$ & $s r$ & $t$ & $B$ & $S E B$ & $\beta$ & $s r$ & $t$ \\
\hline Age & 0.29 & 0.21 & 0.48 & .12 & 1.40 & 0.23 & 0.21 & 0.38 & .09 & 1.14 & 0.22 & 0.21 & 0.36 & .09 & 1.04 \\
\hline Sex & 1.34 & 0.69 & 1.34 & .17 & 1.95 & 0.37 & 0.74 & 0.37 & .04 & 0.51 & 0.23 & 0.78 & 0.23 & .02 & 0.29 \\
\hline FSIQ & 0.05 & 0.03 & 0.51 & .13 & 1.48 & 0.05 & 0.03 & 0.49 & .12 & 1.48 & 0.04 & 0.04 & 0.44 & .09 & 1.04 \\
\hline Sensation seeking & & & & & & 0.42 & 0.24 & 0.76 & .14 & 1.73 & 0.40 & 0.25 & 0.72 & .13 & 1.57 \\
\hline BAS drive & & & & & & -0.07 & 0.16 & -0.17 & -.04 & -0.44 & -0.09 & 0.17 & -0.2 & -.04 & -0.51 \\
\hline BAS fun & & & & & & 0.15 & 0.22 & 0.35 & .06 & 0.69 & 0.15 & 0.23 & 0.34 & .05 & 0.65 \\
\hline BAS reward & & & & & & -0.41 & 0.17 & -0.92 & -.20 & $-2.40^{*}$ & -0.39 & 0.18 & -0.88 & -.18 & $-2.17^{*}$ \\
\hline BIS & & & & & & -0.16 & 0.11 & -0.57 & -.12 & -1.51 & -0.17 & 0.11 & -0.61 & -.13 & -1.54 \\
\hline Verbal EF & & & & & & & & & & & -0.14 & 0.38 & -0.14 & -.03 & -0.38 \\
\hline Spatial EF & & & & & & & & & & & 0.33 & 0.38 & 0.33 & .07 & 0.87 \\
\hline Rule EF & & & & & & & & & & & -0.02 & 0.37 & -0.02 & -.01 & -0.07 \\
\hline Risky EF & & & & & & & & & & & -0.07 & 0.35 & -0.07 & -.02 & -0.20 \\
\hline Motor EF & & & & & & & & & & & -0.02 & 0.35 & -0.02 & -.01 & -0.06 \\
\hline$R^{2}$ & & & & & .07 & & & & & .18 & & & & & .19 \\
\hline$F$ model & & & & & $2.97 *$ & & & & & $3.28 * *$ & & & & & $2.01 *$ \\
\hline$(d f)$ & & & & & $(3,125)$ & & & & & $(8,120)$ & & & & & $(13,115)$ \\
\hline$\Delta F$ & & & & & -- & & & & & $3.30 * *$ & & & & & 0.18 \\
\hline$(d f)$ & 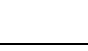 & & & & &  & & & & $(5,120)$ & & & & & $(5,115)$ \\
\hline
\end{tabular}



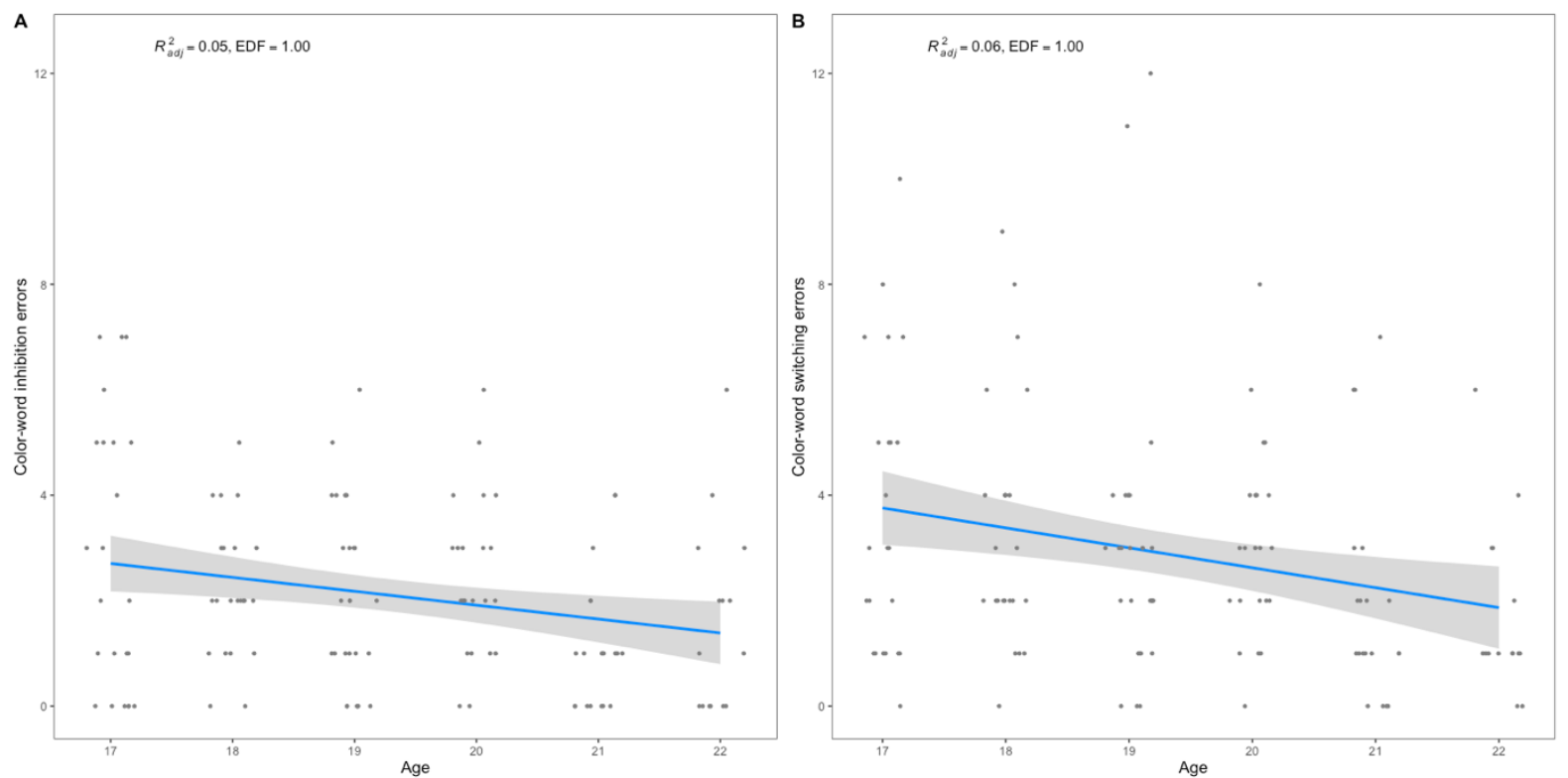

Figure 1. Generalized additive model fits for age effects on color-word inhibition (a) and switching (b) errors.

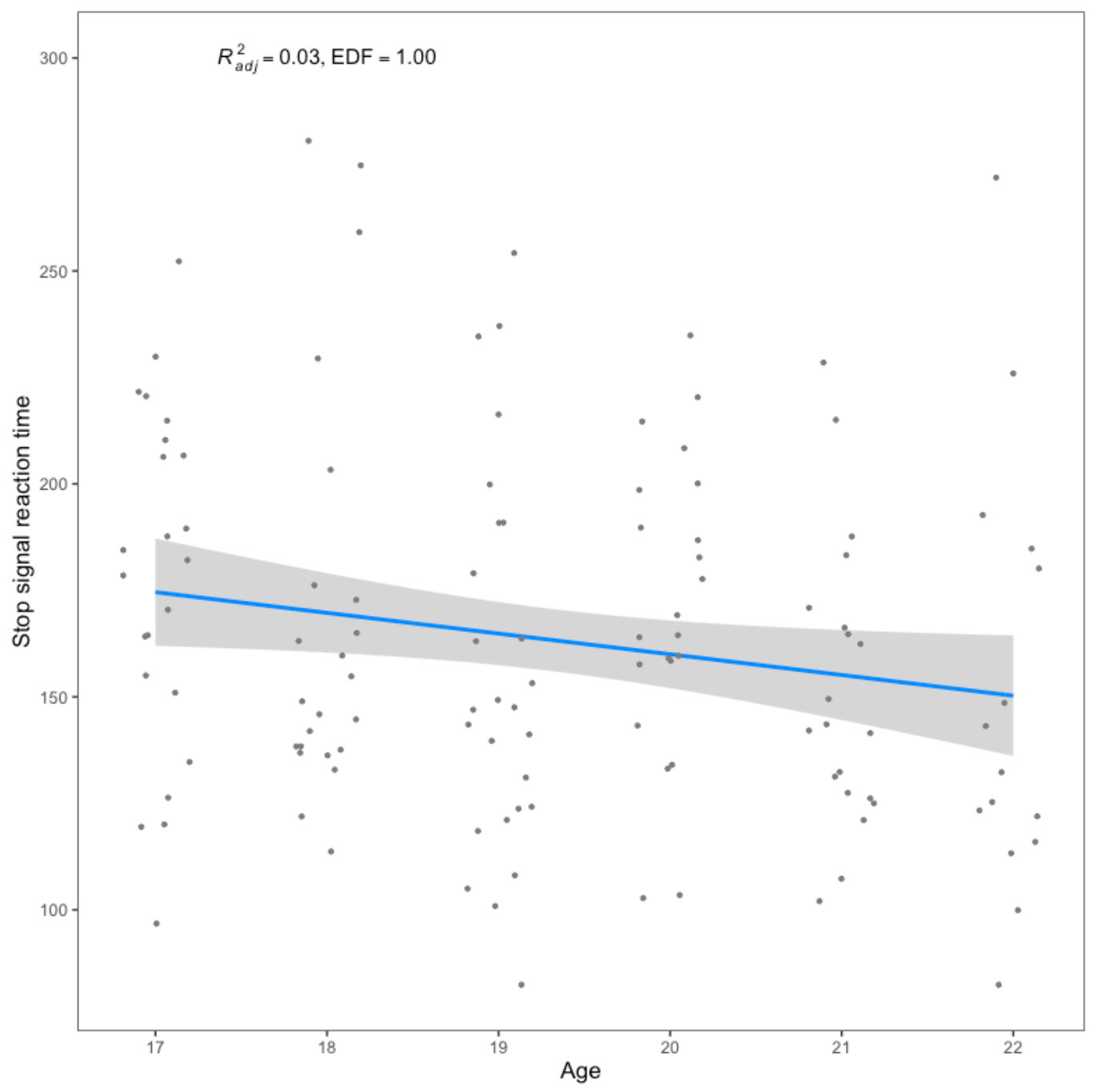

Figure 2. Generalized additive model fit for age effects on stop signal reaction time. 




Figure 3. Generalized additive model fit for age affects on BART adjusted average pumps. 
Supplementary material for "Executive Functions in Late Adolescence and Early Adulthood and their Relationship with Risk-Taking Behavior".

\section{Exploratory Factor Analysis}

An exploratory factor analysis (EFA) was performed on the $27 \mathrm{EF}$ task outcomes described in Table 1. Due to the relatively small sample size, multivariate outlier cases were retained in the analysis. This analytical decision was validated by their exclusion not impacting the pattern of results. A proportion of the EF task outcomes were not normally distributed, including both negative and positive skew. (Tabachnick \& Fidell, 2014) indicate while violations of normality can degrade a factor solution, the results can still be worthwhile. Tabachnick \& Fidell (2014) further suggest that transformation of variables from well-validated, widely reported and published measures may hinder interpretation of results, with D-KEFS and CANTAB measures arguably falling into this category. Further, the principal axis factoring method of estimating factor loadings is robust to some departures from normality. Given these justifications, the task outcomes were left untransformed.

Bivariate correlations (i.e., Pearson's correlation coefficient) among the EF outcome variables were calculated and are displayed in Table S1. Despite the non-normality of some EF variables, Spearman's rank correlations were not used, given Pearson's correlations are recommended to conduct factor analysis. Overall, correlations between different EF tasks were low $(r \leq .40)$, and this outcome was consistent with other studies of EF performance across age (e.g., Anderson, Anderson, Northam, Jacobs, \& Catroppa, 2001; Lee, Bull, \& Ho, 2013; Lehto, Juujärvi, Kooistra, \& Pulkkinen, 2003; Miyake et al., 2000). However, there remained some correlation patterns worthy of note. For all tasks, most outcome scores within tasks were significantly correlated with each other, which was expected and again consistent with previous findings (e.g., Lehto et al., 2003). This suggests that outcomes within a task tap the same construct (e.g., significant correlations among SST outcomes). There was a very high correlation between CGT overall proportion bet and CGT risk-taking $(r=.98)$ due to these variables being calculated similarly. A decision was made to drop CGT risk-taking from further analyses, while CGT overall proportion bet was retained because the latter had more significant correlations with other EF outcome variables. This was done to avoid problems associated with strong multicollinearity and resulted in 26 EF outcome scores available for further analysis. 
Supplementary Table S1.

Correlations (Pearson's r) among executive function task outcomes

\begin{tabular}{|c|c|c|c|c|c|c|c|c|c|c|c|c|c|c|c|c|c|c|c|c|c|c|c|c|c|c|}
\hline & 1 & 2 & 3 & 4 & 5 & 6 & 7 & 8 & 9 & 10 & 11 & 12 & 13 & 14 & 15 & 16 & 17 & 18 & 19 & 20 & 21 & 22 & 23 & 24 & 25 & 26 \\
\hline $\begin{array}{l}\text { 1. Trail switching } \\
\text { time } \\
\text { 2. Trail switching } \\
\text { errors }\end{array}$ & $043 * *$ & & & & & & & & & & & & & & & & & & & & & & & & & \\
\hline 3. Verbal letter & $-0.26^{* * *}$ & -0.09 & & & & & & & & & & & & & & & & & & & & & & & & \\
\hline $\begin{array}{l}\text { 4. Verbal category } \\
\text { 5. Verbal }\end{array}$ & $-0.30^{* * *}$ & 0.10 & $0.42^{* * * *}$ & & & & & & & & & & & & & & & & & & & & & & & \\
\hline switching & $-0.26^{* * *}$ & -0.03 & $0.48^{* * * *}$ & $0.51^{* * * *}$ & & & & & & & & & & & & & & & & & & & & & & \\
\hline $\begin{array}{l}\text { 6. Verbal errors } \\
\text { 7. Color-word }\end{array}$ & 0.08 & 0.10 & 0.10 & 0.01 & 0.00 & & & & & & & & & & & & & & & & & & & & & \\
\hline $\begin{array}{l}\text { inhibition time } \\
\text { 8. Color-word }\end{array}$ & $0.32^{* * *}$ & 0.10 & $-0.22^{*}$ & $-0.32^{* * *}$ & $-0.33^{* * *}$ & -0.13 & & & & & & & & & & & & & & & & & & & & \\
\hline $\begin{array}{l}\text { switching time } \\
\text { 9.Color-word }\end{array}$ & $0.35^{* * * *}$ & 0.03 & $-0.26^{* *}$ & $-0.35^{* * *}$ & $-0.46^{* * * *}$ & -0.08 & $0.57^{* * * *}$ & & & & & & & & & & & & & & & & & & & \\
\hline inhibition errors & -0.06 & 0.10 & -0.11 & 0.03 & -0.06 & 0.00 & $0.29 * *$ & 0.12 & & & & & & & & & & & & & & & & & & \\
\hline $\begin{array}{l}\text { switching errors } \\
\text { s. }\end{array}$ & -0.08 & 0.07 & -0.01 & 0.05 & -0.05 & 0.08 & 0.03 & $0.24 * *$ & $0.30^{* * *}$ & & & & & & & & & & & & & & & & & \\
\hline 11. Tower correct & -0.17 & 0.04 & $0.19^{*}$ & 0.16 & 0.09 & $0.20^{*}$ & $\begin{array}{l}-0.07 \\
-0.07\end{array}$ & -0.13 & 0.14 & -0.04 & & & & & & & & & & & & & & & & \\
\hline $\begin{array}{l}\text { 12. Tower } \\
\text { achievement } \\
\text { 13. Tower }\end{array}$ & -0.14 & -0.09 & $0.19^{*}$ & $0.24^{* *}$ & $0.22^{*}$ & 0.00 & -0.10 & $-0.23^{*}$ & -0.08 & $-0.21^{*}$ & $0.43^{* * *}$ & & & & & & & & & & & & & & & \\
\hline $\begin{array}{l}\text { violations } \\
14 \text {. CGT delay }\end{array}$ & 0.16 & 0.15 & -0.05 & 0.07 & -0.11 & $0.20^{*}$ & $0.20^{*}$ & 0.13 & 0.16 & 0.16 & $-0.21^{*}$ & $-0.24 * *$ & & & & & & & & & & & & & & \\
\hline $\begin{array}{l}\text { aversion } \\
15 \text {. GGT }\end{array}$ & 0.13 & 0.15 & -0.11 & -0.08 & -0.01 & 0.06 & -0.01 & -0.04 & 0.06 & 0.05 & 0.00 & -0.14 & $0.26^{* *}$ & & & & & & & & & & & & & \\
\hline $\begin{array}{l}\text { deliberation time } \\
\text { 16. CGT overall }\end{array}$ & 0.13 & -0.05 & 0.01 & -0.10 & -0.07 & 0.17 & 0.09 & 0.02 & 0.08 & 0.06 & -0.14 & -0.15 & 0.13 & 0.07 & & & & & & & & & & & & \\
\hline $\begin{array}{l}\text { proportion bet } \\
17 \text { GG decision }\end{array}$ & -0.06 & 0.05 & 0.03 & 0.11 & 0.11 & -0.07 & -0.11 & $-0.27 * *$ & 0.06 & -0.09 & -0.04 & 0.13 & 0.12 & 0.08 & 0.03 & & & & & & & & & & & \\
\hline $\begin{array}{l}\text { quality decision } \\
\text { qu CGT risk }\end{array}$ & -0.10 & -0.10 & -0.01 & 0.10 & 0.11 & -0.13 & -0.06 & -0.09 & -0.04 & -0.15 & 0.02 & 0.14 & -0.13 & $-0.38^{* * * *}$ & $-0.59 * * *$ & 0.06 & & & & & & & & & & \\
\hline $\begin{array}{l}\text { adjustment } \\
19 \text { CGT risk }\end{array}$ & -0.05 & -0.01 & 0.10 & 0.07 & 0.03 & -0.02 & 0.00 & 0.01 & -0.09 & -0.10 & 0.14 & 0.16 & $-0.19^{*}$ & $-0.4^{* * * *}$ & $-0.31^{* * * *}$ & $-0.25^{* *}$ & $0.48^{* * * *}$ & & & & & & & & & \\
\hline $\begin{array}{l}\text { taking } \\
\text { 20. IED stages }\end{array}$ & -0.05 & 0.07 & 0.04 & 0.12 & 0.10 & -0.07 & -0.10 & $-0.24 * *$ & 0.07 & -0.09 & -0.02 & 0.14 & 0.10 & 0.09 & 0.03 & $0.98^{* * * *}$ & 0.02 & $-0.20^{*}$ & & & & & & & & \\
\hline $\begin{array}{l}\text { completed } \\
\text { 21. IED total }\end{array}$ & -0.14 & -0.05 & $0.17^{*}$ & 0.12 & 0.09 & 0.10 & -0.02 & -0.06 & -0.03 & -0.02 & $0.27 * *$ & 0.09 & -0.14 & -0.14 & 0.04 & -0.08 & -0.05 & 0.11 & -0.08 & & & & & & & \\
\hline $\begin{array}{l}\text { adjusted errors } \\
\text { 22. SST direction }\end{array}$ & 0.14 & 0.07 & $-0.21^{*}$ & -0.16 & -0.09 & -0.07 & 0.03 & 0.04 & 0.09 & 0.10 & $-0.27 * *$ & -0.11 & 0.14 & $0.19^{*}$ & -0.03 & 0.02 & -0.01 & $-0.21^{*}$ & 0.00 & $-0.89 * * *$ & & & & & & \\
\hline $\begin{array}{l}\text { errors } \\
\text { 23. SST }\end{array}$ & -0.03 & 0.10 & -0.01 & -0.01 & 0.10 & -0.04 & 0.02 & -0.09 & 0.03 & 0.01 & -0.02 & 0.01 & -0.07 & -0.03 & -0.16 & 0.02 & 0.02 & 0.04 & 0.01 & 0.08 & 0.04 & & & & & \\
\hline $\begin{array}{l}\text { proportion } \\
\text { succesful stops } \\
\text { 24. SST correct }\end{array}$ & -0.06 & $-0.19^{*}$ & 0.00 & 0.04 & -0.04 & -0.03 & -0.03 & 0.03 & -0.04 & -0.10 & 0.03 & -0.10 & 0.04 & -0.12 & -0.12 & -0.04 & 0.16 & 0.07 & -0.05 & 0.06 & -0.07 & -0.07 & & & & \\
\hline $\begin{array}{l}\text { reaction time } \\
25 \text { SST SSRT }\end{array}$ & $\begin{array}{c}0.14 \\
-0.09\end{array}$ & $\begin{array}{l}0.04 \\
0.10\end{array}$ & $\begin{array}{l}-0.09 \\
-0.09\end{array}$ & $\begin{array}{l}-0.02 \\
0.07\end{array}$ & -0.04 & 0.01 & 0.10 & 0.11 & 0.03 & 0.07 & $\begin{array}{l}-0.03 \\
0.07\end{array}$ & -0.08 & 0.10 & 0.11 & 0.05 & -0.15 & -0.01 & -0.13 & -0.16 & 0.00 & 0.01 & $-0.51 * * *$ & 0.08 & $030 * * *$ & & \\
\hline $\begin{array}{l}\text { 25. SST SSRT } \\
\text { 26. SWM strategy } \\
\text { 27. SWM total }\end{array}$ & $\begin{array}{l}-0.09 \\
0.11\end{array}$ & $\begin{array}{l}0.10 \\
-0.11\end{array}$ & $\begin{array}{l}-0.099 \\
-0.24^{* * *}\end{array}$ & $\begin{array}{c}0.07 \\
-0.27^{* *}\end{array}$ & $\begin{array}{l}0.07 \\
-0.11\end{array}$ & $\begin{array}{r}-0.14 \\
0.06\end{array}$ & $\begin{array}{l}0.03 \\
0.06\end{array}$ & $\begin{array}{l}0.03 \\
0.02\end{array}$ & $\begin{array}{l}0.15 \\
0.05\end{array}$ & $\begin{array}{c}0.21^{*} \\
0.10\end{array}$ & $\begin{array}{c}0.07 \\
-0.20^{*}\end{array}$ & $\begin{array}{l}0.00 \\
-0.32^{* * *}\end{array}$ & $\begin{array}{c}-0.06 \\
0.13\end{array}$ & $\begin{array}{l}-0.04 \\
0.30^{* * * *}\end{array}$ & $\begin{array}{l}-0.16 \\
0.26 * *\end{array}$ & $\begin{array}{l}0.12 \\
0.05\end{array}$ & $\begin{array}{c}0.01 \\
-0.10\end{array}$ & $\begin{array}{l}0.07 \\
-0.34 * * *\end{array}$ & $\begin{array}{l}0.14 \\
0.01\end{array}$ & $\begin{array}{l}0.11 \\
-0.2^{*}\end{array}$ & $\begin{array}{l}-0.07 \\
0.25^{* *}\end{array}$ & $\begin{array}{l}0.606 \\
-0.06\end{array}$ & $\begin{array}{l}-0.17 \\
-0.05\end{array}$ & $\begin{array}{l}-0.03 \\
0.12\end{array}$ & -0.02 & \\
\hline errors & $0.19^{*}$ & 0.02 & $-0.30^{* * * *}$ & $-0.2^{*}$ & -0.15 & -0.01 & 0.17 & 0.04 & -0.02 & 0.01 & $-0.38^{* * * * *}$ & $-0.37 * * *$ & $0.20^{*}$ & $0.28^{* *}$ & $0.18^{*}$ & 0.05 & -0.06 & $-0.24 * *$ & 0.01 & -0.13 & $0.19^{*}$ & 0.02 & 0.06 & $0.23 * *$ & 0.05 & $0.68 * * *$ \\
\hline
\end{tabular}
Notes. $* p<.05, * * p<.01, * * * p<.001 . \mathrm{CGT}=$ Cambridge gambling task; IED $=$ Intra/extradimensional shift task; $\mathrm{SSRT}=\mathrm{Stop}$ signal reaction time; $\mathrm{SST}=\mathrm{Stop}$ signal
task; SWM $=$ Spatial working memory. 
Both Bartlett's test of sphericity (Bartlett, 1951) and the Kaiser-Meyer-Olkin (KMO) measure of sampling adequacy (MSA; Kaiser \& Rice, 1974) were used to assess the suitability of the data for factor analysis. Bartlett's test was significant, $\chi^{2}(d f=351)$ $=1149.57, p<.001$, suggesting the data were suitable for factor analysis. However, the KMO overall MSA was .59 , suggesting that the level of common variance in the data was in the mediocre range, but still acceptable for conducting factor analysis (Kaiser, 1974). There were six EF task outcome scores that exhibited individual MSA's of .50 or lower (i.e., unacceptable), including trail-making errors (.43), verbal fluency errors (.46), color-word inhibition errors (.49), CGT overall proportion bet (.36), SST direction errors (.48) and SST proportion of successful stops (.41). These outcomes were initially retained in the EFA model estimation process described subsequently.

Factor Determination. To determine the number of factors to best fit the EF battery data, a number of methods were considered, including the old and new Kaiser criteria (i.e., eigenvalues $\geq 1.00$ and 0.70 respectively), Cattell's scree test (Cattell, 1966), Velicer's minimum average partial (MAP) criterion (Velicer, 1976), the very simple structure (VSS) criterion (Revelle \& Rocklin, 1979) and parallel analysis (Horn, 1965). The old Kaiser criteria suggested four factors, while the new criteria suggested five factors. Examination of the scree plot of eigenvalues for the EF outcome measures (see Supplementary Figure S1) did not provide a clear indication of an appropriate number of factors to fit the data, with no welldefined break in the data where eigenvalues flatten out. However, it could be argued that the steepest break in eigenvalues occurred after four factors. The MAP criterion suggested two factors, while the VSS criterion suggested seven factors. Parallel analysis involves comparing eigenvalues obtained from the sample data to eigenvalues obtained from a completely random data set, with factors corresponding to actual eigenvalues greater than the parallel average random eigenvalues retained. Parallel analysis suggested eight factors to best fit the data, which is depicted in Supplementary Figure S1, where eight factors are evident above the simulated random data set. Overall, there was no consensus across the various methods on the most appropriate number of factors to fit to the data, with suggestions of two, four (twice), five, seven and eight factors. 


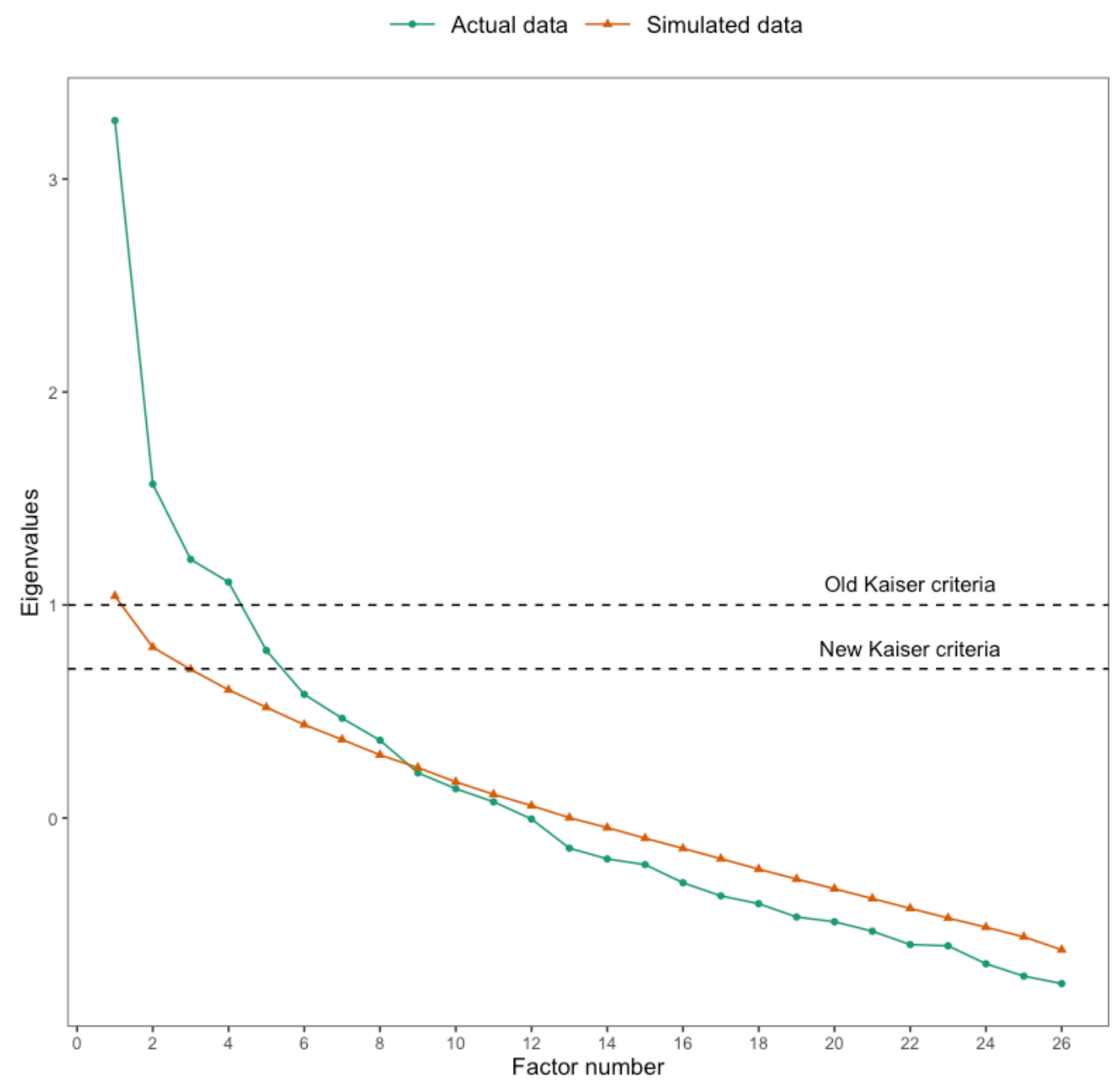

Supplemental Figure S1. Scree plot of eigenvalues for actual and parallel analysis simulated data to determine the number of factors to fit.

Model determination and comparison. Given the variation across factor selection methods in determining the number of factors to include, five separate models were examined, including two-, four-, five-, seven- and eight-factor models. To determine the best fitting factor structure, the models were compared using a range of goodness and residual fit indices. The goodness of fit indices included the Comparative Fit Index (CFI) and the Tucker Lewis Index (TLI), where values range from 0 to 1 , (sometimes above 1 when fit is excellent) with values above .95 and .90 indicating excellent and acceptable fits, respectively (Hu \& Bentler, 1999). The root mean squared error of approximation (RMSEA), and standardized root mean square of the residuals (SRMR) are indices of residual model fit and were used as measures of absolute fit. Lower values represent a better fit of the model to the data, with values of $0.01,0.05$ and 0.08 indicating excellent, good and mediocre fits, respectively (MacCallum, Browne, \& Sugawara, 1996), and a value of 0.10 can be used as a cut-off for a 
poor fitting model. The Bayesian information criterion (BIC) was used as a comparative fit index between models, with lower values representing better fitting models.

The five candidate factor models were initially estimated using the remaining $27 \mathrm{EF}$ outcome variables. At this stage, all EF outcome variables were recoded so that higher values represented better performance to aid in the interpretation of results. In the first round of model estimation, examination of factor loadings across all models indicated that the three variables of verbal fluency errors, CGT overall proportion bet and SST proportion of successful stops did not load significantly on any factor in any model (i.e., loadings $\geq .30$ ). These variables were previously identified as exhibiting low individual MSA scores on the KMO test and were dropped. The five models were re-estimated a second time using the remaining 23 EF outcome variables. Poor loading variables were again detected in the second round of model estimation, including trail-making errors, color-word inhibition and switching errors and tower violations, all of which only loaded adequately on two of the five models. These four variables were dropped, and the remaining $19 \mathrm{EF}$ outcome variables were used in a third and final round of model estimation. Model fit indices are displayed in Supplementary Table S2 for the five different models estimated.

Supplementary Table S2.

Model fit indices for exploratory factor analysis models

\begin{tabular}{lcccccc}
\hline Model & BIC & CFI & TLI & RMSEA & SRMR & $\begin{array}{c}\text { Proportion } \\
\text { Variance }\end{array}$ \\
\hline Two factor & -112.98 & 0.44 & 0.28 & .15 & .12 & .25 \\
Four factor & -233.68 & 0.78 & 0.63 & .11 & .07 & .43 \\
Five factor & -287.86 & 0.94 & 0.88 & .06 & .04 & .51 \\
Seven factor & -212.55 & 0.98 & 0.94 & .04 & .03 & .58 \\
Eight factor & -182.04 & 1.00 & 1.00 & 0.00 & .02 & .63 \\
\hline
\end{tabular}

$\mathrm{BIC}=$ Bayesian Information Criterion; CFI = Comparative Fit Index (incremental measure of fit); RMSEA = Root Mean Square Error of Approximation (absolute measure of residual fit); SRMR = Standardized Root Mean Square of the Residuals (absolute measure of residual fit); TLI = Tucker-Lewis Index (incremental measure of fit).

To aid in selecting the best fitting EFA model, overall model fit indices were compared and contrasted for the five models. As evident in Supplementary Table S2, the two-factor model exhibited poor fit across all indices. In this model, the stop signal outcomes failed to load adequately on any of the two factors. The four-factor model approached adequate fit, although the factors were not easily interpretable in terms of the factor loading patterns. For example, Tower, CGT and SWM task outcomes all loaded on a single factor. The five- and seven-factor models exhibited adequate-to-good fit to the data. However, both 
of these models contained Heywood cases (Heywood, 1931) ${ }^{1}$, which are typically taken to be indicative of a misspecified model and/or data that violate assumptions of the common factor model (e.g, non-normality, small sample sizes; Fabrigar, Wegener, MacCallum, \& Strahan, 1999). Finally, the eight-factor model exhibited excellent fit to the data. On examination of the patterns of variable loadings across the five models, it was observed that as the number of factors increased across models, there was a tendency for EF outcome variables to load within the respective tasks they were derived from. For example, outcomes derived from the CGT would load on the same factor in the five-, seven- and eight-factor models. This may have reflected the possibility that each EF task measured a unique combination of EF abilities. For the eight-factor model, each factor essentially represented one of the eight tasks used to assess EF ability among participants, although cross-loading variables were evident for CGT outcomes.

Despite the eight-factor model exhibiting the best absolute fit to the data, four of the factors only consisted of two adequately loading variables. As highlighted by (Fabrigar et al., 1999), it is generally recommended that factors consist of at least three adequately loading variables. Given this, a more parsimonious approach in selecting an appropriate number of factors for the final model was taken to balance between the fewest number of factors and interpretability of the factors, thereby increasing the number of variables available to load on each factor. Using this approach, and while also considering the fit indices, the five-factor model appeared to provide the most appropriate fit to the data with a factor structure that was clearly interpretable (see Supplementary Table S3) and accounted for about 51\% of the common variance in the data. It is noted that one Heywood case was evident in the five-factor model (i.e., CGT decision-making). As argued by (Fabrigar et al., 1999), there are situations where the presence of Heywood cases may not represent a misspecified model and might not be problematic. For example, in situations where population parameters are close to boundaries (i.e., true population communalities close to 1), Heywood cases may emerge due to variability resulting from sampling error. Additionally, for the current results, Heywood cases might have emerged due to restricted ranges of variance in the EF task outcomes among the sample studied (e.g., ceiling and floor effects), resulting in violations of normality. Further, given the clear interpretability of the factor solution for the five-factor model, the presence of Heywood cases may not be a serious problem (Crites, Fabrigar, \& Petty, 1994; Fabrigar et al., 1999).

\footnotetext{
${ }^{1}$ Heywood cases occur when the communality for a measured variable (i.e., the proportion of variance in the measured variable accounted for by the common factors) is estimated to be at 1 or greater than 1 .
} 


\section{Supplementary Table S3.}

Factor loadings, communalities, errors, and proportions of variance for the final five-factor exploratory factor analysis model for executive function measures

\begin{tabular}{|c|c|c|c|c|c|c|c|}
\hline \multirow[b]{2}{*}{ Outcome } & \multicolumn{5}{|c|}{ Factor $^{\dagger}$} & \multirow[b]{2}{*}{$h^{2}$} & \multirow[b]{2}{*}{$u^{2}$} \\
\hline & One & Two & Three & Four & Five & & \\
\hline Trail-making time & 0.43 & 0.08 & 0.08 & 0.06 & -0.05 & 0.24 & 0.76 \\
\hline Verbal fluency letter & 0.46 & 0.23 & 0.11 & -0.08 & 0.07 & 0.34 & 0.66 \\
\hline Verbal fluency category & 0.56 & 0.15 & 0.06 & 0.03 & 0.03 & 0.39 & 0.61 \\
\hline Verbal fluency switching & 0.68 & 0.02 & 0.02 & 0.02 & -0.03 & 0.47 & 0.53 \\
\hline Color-word inhibition time & 0.61 & 0.00 & -0.06 & 0.01 & 0.03 & 0.36 & 0.64 \\
\hline Color-word switching time & 0.76 & -0.11 & -0.03 & 0.02 & -0.03 & 0.55 & 0.45 \\
\hline SWM strategy score & -0.03 & 0.73 & 0.07 & 0.07 & -0.03 & 0.57 & 0.43 \\
\hline SWM total errors & 0.03 & 0.91 & -0.04 & -0.06 & 0.02 & 0.81 & 0.19 \\
\hline Tower total correct & 0.12 & 0.33 & 0.19 & -0.02 & 0.02 & 0.20 & 0.80 \\
\hline Tower achievement score & 0.20 & 0.40 & 0.02 & 0.06 & 0.02 & 0.25 & 0.75 \\
\hline IED stages completed & 0.01 & -0.04 & 0.93 & -0.04 & -0.05 & 0.86 & 0.14 \\
\hline IED adjusted errors & 0.00 & 0.02 & 0.96 & 0.02 & 0.04 & 0.94 & 0.06 \\
\hline CGT delay aversion & -0.09 & 0.27 & 0.13 & 0.32 & -0.03 & 0.22 & 0.78 \\
\hline CGT deliberation time & -0.01 & -0.18 & 0.07 & -0.50 & 0.14 & 0.33 & 0.67 \\
\hline CGT decision-making & 0.02 & -0.05 & -0.01 & 1.08 & 0.02 & 1.15 & -0.15 \\
\hline CGT risk-adjustment & 0.11 & -0.30 & -0.12 & -0.46 & 0.05 & 0.36 & 0.64 \\
\hline SST direction errors & -0.01 & 0.02 & 0.01 & 0.01 & 0.98 & 0.96 & 0.04 \\
\hline SST median correct RT & -0.05 & -0.20 & 0.07 & 0.03 & 0.51 & 0.31 & 0.69 \\
\hline SST SSRT & 0.02 & 0.04 & -0.09 & -0.03 & 0.62 & 0.39 & 0.61 \\
\hline Proportion variance & .12 & .11 & .10 & .09 & .09 & & \\
\hline
\end{tabular}

Salient structure loadings for variables within factors are shaded to aid interpretation.

$h^{2}=$ Communality or common variance; $u^{2}=$ error or unique variance.

'Factor labels:

One - Verbal inhibition and flexibility

Two - Spatial working memory and planning

Three - Rule acquisition and switching

Four - Risky decision-making

Five - Motor inhibition

The first factor accounted for the most variance, consisted of the most varied task outcomes, with the highest loadings including all verbal fluency, trail making, and colorword inhibition outcomes, and was labelled as verbal inhibition and flexibility. Language abilities underpin performance on these task outcomes. Both the verbal fluency and trailmaking tasks draw on the abilities to think flexibly, switch response sets, self-regulate and self-monitor (Lezak, Howieson, Bigler, \& Tranel, 2012). The color-word inhibition task assesses the ability to selectively inhibit or suppress a prepotent verbal response. SWM and tower task outcomes exhibited the highest loadings on the second factor, which was labelled as spatial working memory and planning, given these tasks arguably require participants to retain and manipulate spatial information, as well as solve problems in spatial space. The third factor consisted of the two IED outcomes with the highest loadings, which was labelled as rule acquisition and shifting. It is acknowledged that only two variables loaded on this 
factor, however, there was an example of this occurring in all models estimated apart from the two-factor model. CGT outcomes had the highest loadings on the fourth factor, which was labelled as risky decision-making. This factor may best represent hot EF, given only CGT outcomes loaded adequately. SST outcomes loaded most strongly on the fifth factor, which was labelled as motor inhibition, given the SST requires individuals to inhibit a motor response in response to an auditory signal.

Factor Scores. Factor scores for participants were estimated from the five-factor model using the method proposed by (ten Berge, Krijnen, Wansbeek, \& Shapiro, 1999) that calculates factors scores while preserving correlations between factors for oblique solutions. Bivariate correlations (i.e., Pearson's correlation coefficient) among the five-factor model EF factor scores were calculated and are displayed in Supplementary Table S4. The spatial working memory factor was significantly and positively correlated with the rule acquisition and switching $(r=.24)$, and verbal inhibition and switching $(r=.20)$ factors. Overall, correlations between the EF factors were predominately low in magnitude. This may suggest that $\mathrm{EF}$, as measured in the current study, is best represented by a set of separable components.

Supplementary Table S4.

Correlations (Pearson's r) among executive function factor scores.

\begin{tabular}{lcccc}
\hline & 1 & 2 & 3 & 4 \\
\hline 1. Verbal inhibition and flexibility & & & & \\
2. Spatial working memory and planning & $0.20^{*}$ & & & \\
3. Rule acquisition and shifting & 0.11 & $0.24^{*}$ & 0.01 & -0.04 \\
4. Risky decision making & 0.09 & 0.13 & -0.03 & \\
5. Motor inhibition & -0.06 & -0.03 & &
\end{tabular}

\section{References}

Anderson, V. A., Anderson, P., Northam, E., Jacobs, R., \& Catroppa, C. (2001). Development of executive functions through late childhood and adolescence in an Australian sample. Developmental Neuropsychology, 20(1), 385-406. doi:10.1207/S15326942DN2001_5

Bartlett, M. S. (1951). The effect of standardization on a chi square approximation in factor analysis. Biometrika, 38, 337-344.

Cattell, R. B. (1966). The scree test for the number of factors. Multivariate Behavioral Research, 1(2), 245-276. doi:10.1207/s15327906mbr0102_10

Crites, S. L., Fabrigar, L. R., \& Petty, R. E. (1994). Measuring the Affective and Cognitive Properties of Attitudes: Conceptual and Methodological Issues. Personality and Social Psychology Bulletin, 20(6), 619-634. doi:10.1177/0146167294206001

Fabrigar, L. R., Wegener, D. T., MacCallum, R. C., \& Strahan, E. J. (1999). Evaluating the 
use of exploratory factor analysis in psychological research. Psychological Methods, 4(3), 272-299.

Heywood, H. B. (1931). On finite sequences of real numbers. Proceedings of the Royal Society of London. Series A, Containing Papers of a Mathematical and Physical Character, 134(824), 486-501.

Horn, J. L. (1965). A rationale and test for the number of factors in factor analysis. Psychometrika, 30, 179-185.

Hu, L., \& Bentler, P. M. (1999). Cutoff criteria for fit indexes in covariance structure analysis: Conventional criteria versus new alternatives. Structural Equation Modeling: A Multidisciplinary Journal, 6(1), 1-55. doi:10.1080/10705519909540118

Kaiser, H. F. (1974). An index of factorial simplicity. Psychometrika, 39(1), 31-36.

Kaiser, H. F., \& Rice, J. (1974). Little Jiffy, Mark IV. Educational \& Psychological Measurement, 34, 111-117.

Lee, K., Bull, R., \& Ho, R. M. (2013). Developmental changes in executive functioning. Child Development, 84(6), 1933-1953. doi:10.1111/cdev.12096

Lehto, J. E., Juujärvi, P., Kooistra, L., \& Pulkkinen, L. (2003). Dimensions of executive functioning: Evidence from children. British Journal of Developmental Psychology, 21(1), 59-80. doi:10.1348/026151003321164627

Lezak, M. D., Howieson, D. B., Bigler, E. D., \& Tranel, D. (2012). Neuropsychological assessment (5th ed.). New York: Oxford University Press.

MacCallum, R. C., Browne, M. W., \& Sugawara, H. M. (1996). Power analysis and determination of sample size for covariance structure modeling. Psychological Methods, 1(2), 130-149. doi:10.1037/1082-989X.1.2.130

Miyake, A., Friedman, N. P., Emerson, M. J., Witzki, A. H., Howerter, A., \& Wager, T. D. (2000). The unity and diversity of executive functions and their contributions to the complex "frontal lobe" tasks: A latent variable analysis. Cognitive Psychology, 41, 49-100. doi:10.1006/cogp.1999.0734

Revelle, W., \& Rocklin, T. (1979). Very simple structure - alternative procedure for estimating the optimal number of interpretable factors. Multivariate Behavioral Research, 14(4), 403-414. doi:10.1207/s15327906mbr1404_2

Tabachnick, B. G., \& Fidell, L. S. (2014). Using multivariate statistics (Sixth ed.). London: Pearson.

ten Berge, J. M. F., Krijnen, W. P., Wansbeek, T., \& Shapiro, A. (1999). Some new results on correlation-preserving factor scores prediction methods. Linear Algebra and its Applications, 289(1), 311-318. doi:10.1016/S0024-3795(97)10007-6

Velicer, W. F. (1976). Determining the number of components from the matrix of partial correlations. Psychometrika, 41, 321-327. 